Z. Phys. Chem. 216 (2002) 305-332

(C) by Oldenbourg Wissenschaftsverlag, München

\title{
Intramolecular Photoinduced Electron Transfer in Zwitterionic Quinolinium Dyes - Experimental and Theoretical Studies
}

\author{
By Th. Engel ${ }^{1, *}$, G. Käb ${ }^{2}$ and H. Lanig ${ }^{1}$ \\ ${ }^{1}$ Computer Chemistry Center, University of Erlangen-Nürnberg, Nägelsbachstr. 25, \\ D-91052 Erlangen, Germany \\ 2 Max-Planck-Institut für Biophysikalische Chemie, Am Faßberg 11, \\ D-37077 Göttingen, Germany
}

Dedicated to Prof. Dr. Friedemann W. Schneider

(Received November 5, 2001; accepted December 3, 2001)

\section{Fluorescence / Intramolecular Electron Transfer / Marcus Theory / Betaine / Semiempirical Calculations}

Quinolinium cations and quinolinium betaines were investigated in the representative solvents water and acetonitrile at room temperature using stationary and time-resolved fluorescence spectroscopy (Single-Photon-Counting-method).

Experimental results reveal that sulfoalkyl- and carboxyalkyl-quinolinium compounds display a strikingly different behavior in the two solvents. Furthermore, the fluorescence lifetime depends on the length of the spacer for the sulfoalkyl compounds in acetonitrile and the carboxyalkyl compounds in water, respectively. This suggests an intramolecular interaction of the anionic headgroups with the quinolinium system in the excited state. To support this idea, different positions at the chromophore are substituted by a methylgroup in order to perturb the proposed interaction.

With the intention to understand the dynamics of the postulated photoinduced electron transfer from the anionic group onto the excited quinolinium chromophore, semiempirical quantum chemical calculations were performed on the species using the PM3 hamiltonian including solvent effects by a self consistent reaction field (SCRF).

We show that the Marcus theory of electron transfer may serve as a theoretical basis for a natural interpretation of the dynamic fluorescence quenching behavior.

\section{Introduction}

Photochemically excited molecules often act as strong oxidizing or reducing agents. Therefore, photoinduced electron transfer (PeT) processes and elec-

* Corresponding author. E-mail: thomas.engel@chemie.uni-erlangen.de 
tron transfer (eT) reactions are of fundamental importance both in all branches of photochemistry [1], and in general chemistry, physics and biology [2-5]. To understand and utilize the factors that control biological eT processes as well as the accumulated knowledge in constructing artificial photosynthetic systems [6] provides a major motivation for current research on eT and PeT.

The inverted region predicted by the classical eT theory of Marcus [7] has taken a central position in the development of theory and its experimental verification [8]. In this regime, the rate of electron transfer should decrease at large thermodynamic driving forces $(-\Delta G>\lambda)$, i.e. when the driving force $-\Delta G$ becomes larger than the reorganization energy $\lambda$. Although well established, the inverted region escaped experimental verification until the late 70 s/early 80s $[9,10]$. In bimolecular fluorescence quenching via exciplexes or charge separation PeT [11] however, no evidence was found for a decrease of quenching efficiency at large driving forces. On the other hand, the nonradiative return of photogenerated ion pairs to the electronic ground state of the donor-acceptor system via charge recombination followed an inverted regime behavior [12]. It seems to be commonly accepted that to display inverted region behavior, the distance of donor and acceptor has to be constrained, e.g. by a rigid matrix [9], rigid donor-acceptor linking units [10] or coulombic forces [12]. Therefore the actual electron transfer step becomes 'unimolecular' in a wider sense, even for bimolecular or quasi-bimolecular/supramolecular PeT systems [13-16]. Apart from effects of diffusion control in bimolecular eT processes, the reason for this fixed-distance requirement is traced back to the distance dependence of the factors controlling the $\mathrm{T}$ rate coefficient. These factors are especially the electron exchange matrix element and the solvent or outer-sphere reorganization energy. The solvent reorganization becomes larger at larger D-A distances, favoring longer transfer distances in the inverted regime, if possible.

Zwitterionic (betaine type) intramolecular donor-acceptor systems, as described in the present work, provide ideal models to probe inverted region effects by direct fluorescence quenching experiments via change of the donor and the solvent polarity. Charge recombination PeT has the particular advantage that by decreasing the solvent polarity the PeT driving force is increased, while the solvent reorganization energy is decreased.

Apart from the influence of energetics on the rates of electron transfer processes, the distance and relative orientation of donor and acceptor determines the rate in the electronically non-adiabatic limit via the electronic coupling matrix element [17-20]. In our model systems, anionic intramolecular fluorescence quenchers are linked to a quinolinium chromophore via alkyl chains of different length attached to the quinolinium N-atom (Fig. 1). The flexibility of the alkyl chain allows the formation of intramolecular complexes via coulombic forces between the counter ions (Fig. 2). The complex stability may depend to some extent on the solvent. By varying the length of the alkyl linking unit as well as by introducing methyl substitutents (steric hindrance) at various positions of the aromatic fluorophore the stability of cyclic complexes, as well 
<smiles></smiles>

\begin{tabular}{lccc}
\hline $\mathbf{D}^{-}$ & R (position) & n & class \\
\hline $\mathrm{H}$ & $\mathrm{H}$ & $2-4$ & $\mathrm{~A}$ \\
$\mathrm{SO}_{3}{ }^{-}$ & $\mathrm{H}$ & $2-4$ & $\mathrm{~B}$ \\
$\mathrm{SO}_{3}{ }^{-}$ & $\mathrm{CH}_{3}(2)$ & $2-4$ & $\mathrm{C}$ \\
$\mathrm{CO}_{2}{ }^{-}$ & $\mathrm{H}$ & $2-4$ & $\mathrm{D}$ \\
$\mathrm{H}$ & $\mathrm{CH}_{3}(2)-\mathrm{CH}_{3}(8)$ & 2 & $\mathrm{E}$ \\
$\mathrm{SO}_{3}{ }^{-}$ & $\mathrm{CH}_{3}(2)-\mathrm{CH}_{3}(8)$ & 2 & $\mathrm{~F}$
\end{tabular}

Fig. 1. N-alkyl-quinolinium compounds with different chain lengths $(n)$, headgroups $\left(\mathrm{D}^{-}\right)$ and substituents (R) arranged in six classes [1-alkyl-quinolinium cation (class A); 1-sulfoalkyl-quinolinium betaine (class B); 2-methyl-1-sulfoalkyl-quinolinium betaine (1-sulfoalkyl-quinaldinium) (class C); 1-carboxyalkyl-quinolinium betaine (class D); $\mathrm{X}$-methyl-1-ethyl-quinolinium cation (class E); X-methyl-1-sulfoethyl-quinolinium betaine (class F)]. Hexafluorophosphate is the counterion of the cations of class A and E.

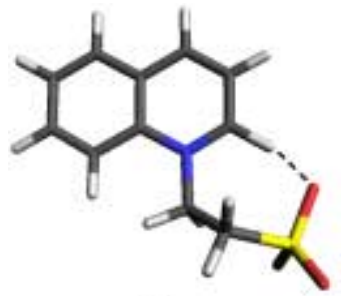

(a)

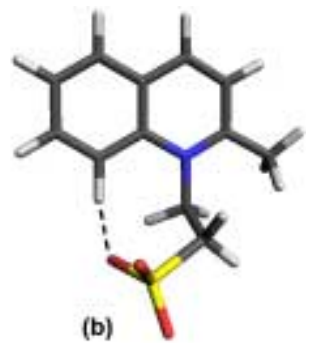

(b)

Fig. 2. Most favorable cyclic arrangement of the side chain of representative compounds of class B and C (1-sulfoethyl-quinolinium- (a) and 2-methyl-1-sulfoethyl-quinolinium betaine (b)) according to semiempirical calculations (s. Sect. 2.2). Cyclic arrangement of the side chain to the $\mathrm{C} 2$ and the $\mathrm{C} 8$ position of the aromatic body, respectively, is illustrated by dashed lines.

as the relative orientation of electron donor (anionic quencher) and acceptor (quinolinium fluorophore) may be controlled.

\section{Overview of previous research results}

To integrate the results of this study in a comprehensive context, this chapter briefly summarizes already published data [21-26].

\subsection{Fluorescence decay time}

In the following sections mainly fluorescence decay times will be discussed, because these values are significant to the characteristics of the compound classes and of the particular solvent. Additional fluorescence spectroscopic 
Table 1. Fluorescence decay time $\tau_{\mathrm{f}}$ and the non-radiating contributions of the fluorescence deactivation $k_{\mathrm{nf}}$ (s. Sect. 4.2) of quinolinium compounds (classes A-D) with different chain lengths $(n)$ and headgroups $\left(\mathrm{D}^{-}\right)$in the solvent water and acetonitrile at $298 \mathrm{~K}$. (" biexponential behavior, s. Sect. 3).

\begin{tabular}{|c|c|c|c|c|c|c|c|}
\hline & \multirow[t]{2}{*}{ Compound } & \multirow{2}{*}{$\begin{array}{c}\text { Chain } \\
\text { length } \\
n\end{array}$} & \multirow{2}{*}{$\begin{array}{c}\text { Compound } \\
\text { Nr. }\end{array}$} & \multicolumn{2}{|c|}{$\begin{array}{c}\text { Fl.-decay time } \\
\tau_{\mathrm{f}}[\mathrm{ns}]\end{array}$} & \multicolumn{2}{|c|}{$\begin{array}{c}\text { Velocity rate } \\
k_{\mathrm{nf}}\left[\mathrm{s}^{-1}\right]\end{array}$} \\
\hline & & & & $\mathrm{H}_{2} \mathrm{O}$ & $\mathrm{CH}_{3} \mathrm{CN}$ & $\mathrm{H}_{2} \mathrm{O}$ & $\mathrm{CH}_{3} \mathrm{CN}$ \\
\hline class A & & $\begin{array}{l}2 \\
3 \\
4\end{array}$ & $\begin{array}{l}(1) \\
(2) \\
(3)\end{array}$ & $\begin{array}{l}14.3 \\
14.3 \\
14.4\end{array}$ & $\begin{array}{l}21.7 \\
21.8 \\
21.8\end{array}$ & $\begin{array}{l}3.6 \cdot 10^{7} \\
3.6 \cdot 10^{7} \\
3.7 \cdot 10^{7}\end{array}$ & $\begin{array}{l}8.2 \cdot 10^{6} \\
8.2 \cdot 10^{6} \\
8.2 \cdot 10^{6}\end{array}$ \\
\hline class B & & $\begin{array}{l}2 \\
3 \\
4\end{array}$ & $\begin{array}{l}(4) \\
(5) \\
(6)\end{array}$ & $\begin{array}{l}14.2 \\
13.2 \\
14.2\end{array}$ & $\begin{array}{l}0.3 \\
1.2 \\
1.0\end{array}$ & $\begin{array}{l}4.0 \cdot 10^{7} \\
4.3 \cdot 10^{7} \\
3.7 \cdot 10^{7}\end{array}$ & $\begin{array}{l}3.3 \cdot 10^{9} \\
7.8 \cdot 10^{8} \\
9.0 \cdot 10^{8}\end{array}$ \\
\hline class $\mathrm{C}$ & $\begin{array}{l}\left.\mathrm{C}^{\mathrm{H}}\right)_{\mathrm{n}} \\
\mathrm{so}_{3}^{-}\end{array}$ & $\begin{array}{l}2 \\
3 \\
4\end{array}$ & $\begin{array}{l}(7) \\
(8) \\
(9)\end{array}$ & $\begin{array}{l}13.6 \\
15.1 \\
14.3\end{array}$ & $\begin{array}{l}3.6 \\
2.5 \\
2.0\end{array}$ & $\begin{array}{l}4.2 \cdot 10^{7} \\
3.4 \cdot 10^{7} \\
3.6 \cdot 10^{7}\end{array}$ & $\begin{array}{l}2.6 \cdot 10^{8} \\
3.6 \cdot 10^{8} \\
2.2 \cdot 10^{8}\end{array}$ \\
\hline class D & $\begin{array}{l}\left(\mathrm{CH}_{2}\right) \\
1 \\
\mathrm{CO}_{2}^{-}\end{array}$ & $\begin{array}{l}2 \\
3 \\
4\end{array}$ & $\begin{array}{l}(10) \\
(11) \\
(12)\end{array}$ & $\begin{array}{l}0.47^{*} \\
3.28^{*} \\
5.80^{*}\end{array}$ & $\begin{array}{l}23.1 \\
22.5 \\
21.2\end{array}$ & $\begin{array}{l}1.9 \cdot 10^{9} \\
2.4 \cdot 10^{8} \\
1.4 \cdot 10^{8}\end{array}$ & $\begin{array}{l}1.7 \cdot 10^{7} \\
1.7 \cdot 10^{7} \\
1.2 \cdot 10^{7}\end{array}$ \\
\hline
\end{tabular}

data (quantum yields, maximum of absorption and emission spectra) may be found in the literature [21-23].

The apparent fluorescence decay time of the classes A, B, C and D (Table 1; Fig. 5 yz-plane) can be systematically classified in two categories: category 1 with long decay times and category 2 with short decay times.

\section{Category 1:}

The fluorescence decay times of class $\mathbf{A}$ (cationic reference compounds) have the highest values $(\sim 22 \mathrm{~ns})$ in $\mathrm{CH}_{3} \mathrm{CN}$ as solvent. The typical quantum yield for quinolinium cations $(\sim 0.80)[21]$ shows that the aprotic solvent has no influence on the deactivation efficiency. The members of the cationic compound class, show no significant deviation in the fluorescence decay time which confirms no dependency on the alkyl chain length.

In water the betaines of the class $\mathbf{B}$ and $\mathbf{C}$ show the same principal behavior as the cations of class A. The hydrophilic headgroup of the betaine is 
surrounded by solvent molecules, obstructing an interaction of the anionic part of the molecule with the cationic chromophore by intramolecular Coulomb forces. Therefore, the decay times of the betaines (class B and C) are similar to those of the $\mathrm{N}$-alkyl-quinolinium cations (class $\mathrm{A}$ ) in water, and depend only weak on the length of the sidechain [23].

It should be noticed that the fluorescence behavior of class $\mathbf{D}$ molecules (with the anion of a weak acid; $\mathrm{D}^{-}=\mathrm{CO}_{2}{ }^{-}$) in acetonitrile, is comparable to the solvent behavior of the $\mathrm{N}$-sulfoalkyl betaines of class B in water. Thus, the carboxy headgroup scarcely shows interaction with the chromophore in acetonitrile and therefore the fluorescence decay times are comparable with those of the reference class $\mathrm{A}$ in acetonitrile.

\section{Category 2:}

A significant decrease (from $\sim 22$ ns to $\sim 14$ ns) of quinolinium derivatives (1), (2), and (3) of class A takes place when changing the solvent from acetonitrile to the more polar and protic water. In parallel, the quantum yield declines to $\sim 0.50$ [21]. Similar to the quinolinium cations of class $\mathrm{A}$ in $\mathrm{CH}_{3} \mathrm{CN}$, the length of the alkyl chain has no significant effect on the fluorescence lifetime. The reduced quantum yield and decreased fluorescence decay time may be attributed to the quenching effect of $\mathrm{H}_{2} \mathrm{O}$ as published in [24].

Despite the small solubility in acetonitrile, the betaines of class $\mathbf{B}$ and $\mathbf{C}$ undergo a very strong fluorescence quenching compared to the cations of class A. This effect was attributed to the anionic headgroup, whereby an intramolecular cyclic complex was assumed (Fig. 2) [23, 24]. For both classes (B and C) the interaction of the headgroups with the chromophore strongly depends on the chain length.

In contrast to class $\mathrm{B}$ and $\mathrm{C}$, the carboxy-headgroup of the molecules of class $\mathbf{D}$ turns out to be a very efficient quencher in water. Again, the solvent with short decay times, shows a strong dependency of the fluorescence lifetimes on the chain length.

\subsection{Semiempirical calculations}

Since neither absorption nor emission spectra change location and shape of the bands in the respective solvent, an exciplex formation can be excluded [23]. Nevertheless, a high efficiency of quenching caused by an interaction of the headgroup with the fluorophore is observed, probably modulated by different linker conformations (see Table 1). To support this assumption, semiempirical calculations were performed (see Sect. 4.3), which explicitly considered the distance and relative orientation of the polar headgroup and the energy of certain molecular conformations. The main result of the conformational analysis, which was performed for the gas phase, is an energetically most favorable cyclic conformation which represents the precursor or initial state of 
the quenching process (Fig. 2). Due to the stability of this complex, it is reasonable that this conformation is maintained during the electronic excitation. The stabilization of this intramolecular complex is highest for the N-sulfoethyl compound (4). The molecules within class B show less degrees of freedom in motion of the side chain and a higher stability of the low-energy cyclic conformation, expressed experimentally in the short decay time of $0.3 \mathrm{~ns}$ (4). The calculations indicate that the energetically preferred position of the headgroup is next to the carbon $\mathrm{C} 2$ of the heterocycle.

The interaction between the anionic headgroup and the fluorophore is prevented when this position is blocked by methylation (class C). The decay times increase in acetonitrile up to $\sim 3 \mathrm{~ns}$ compared to the sterically non-hindered compounds of class B (Table 1). However, the direct comparison of the fluorescence decay behavior of the classes $\mathrm{B}$ and $\mathrm{C}$ is based on the assumption that radiationless transition rates (IC, ISC) do not significantly change (Table 1, Sect. 4.2) [21], despite the presence of a methyl substituent at the chromophore. This should also apply to the native lifetimes.

If the postulated and semiempirically predicted cyclic arrangement, i.e. the close approach of the negatively charged headgroup to the positively charged chromophore, is sterically hindered by a methyl group at position C2, a reorientation of the alkyl chain to $\mathrm{C} 8$ takes place. In this case the electrostatic interaction is not as strong as in the case of the orientation of the headgroup to $\mathrm{C} 2$. This intramolecular interaction therefore provides a direct measure of the fluorescence deactivation behavior. The electronic interaction between fluorophore and quencher within the intramolecular complex, and thus the efficiency of the fluorescence quenching, is determined by the orientation of the interacting orbitals ( $\pi$-system of the excited aromatic ring and a non-bonding p-orbital of the closest oxygen atom, Fig. 8), which is modulated by the dynamic of the sidechain $[23,25]$.

The postulated model, resulting from the conformational analysis for the gas phase, explains the deactivation of the fluorescence by energy redistribution between the fluorophore and the quencher via a $\mathrm{C}-\mathrm{H} \cdots \mathrm{O}$ vibrational mode [23]. This assumption is based on an enlargement of the corresponding $\mathrm{C}-\mathrm{H}$ bond length, which interacts with the $\mathrm{SO}_{3}{ }^{-}$headgroup (s. Sect. 4.3), combined with a reduction of the bond order. The result of this intramolecular complex is a $\mathrm{C}-\mathrm{H} \cdots \mathrm{O}$ oscillation as an "internal sphere mode", transferring energy from the chromophore to the quenching group. However, due to the small variation of the bond length $(\Delta \mathrm{C}-\mathrm{H} \sim 0.1 \AA)$, the model of a "proton shift" has been given up in favor of an electron transfer model [23, 26].

\subsection{Application of the Electron Transfer Theory of Marcus, Jortner and Bixon}

In the interpretation of the fluorescence deactivation behavior, two types of quenching processes may be considered: Förster energy transfer (FET) and 
electron transfer (eT) [26,27]. FET could be ruled out due to the negligible spectral overlap of the emission and absorption spectra of energy donor and acceptor [27], respectively, where the positive chromophore acts as the energy donor $\left(\lambda_{\max }(\mathrm{em})=.410 \mathrm{~nm}\right)$. The energy-acceptor $\mathrm{D}^{-}$absorbs in the $\mathrm{UV}$, and therefore FET would be energetically uphill (endothermic).

The positively charged quinolinium chromophore is to be considered as an oxidizing agent even in the electronic ground state. Upon optical excitation its oxidation potential is further increased, while the negatively charged sulfonato and carboxylato groups may be (easily) oxidized in the locally excited (LE) state of quinolinium betaines. Therefore, intramolecular electron transfer (eT) is assumed to be the operative fluorescence quenching mechanism in these model systems, where the charged moiety $\mathrm{D}^{-}$acts as the electron donor.

Both the ISC rate and the radiative rate are not influenced by the length of the alkyl chain (s. Sect. 4.3). This was confirmed by the observation that all molecules of class A exhibit the same fluorescence decay times and quantum yields in the same solvent, irrespective of the chain length [23]. Therefore, electron transfer quenching is assumed to be the only additional channel of fluorescence deactivation introduced in the betaines as compared to the compounds of class A. Based on this assumption, experimental eT rates $\left(k_{\exp }{ }^{\mathrm{eT}}\right)$ were calculated as the difference between the reciprocal decay time of the betaine and the appropriate reference compound without a quenching headgroup (class A) according to Eq. (1).

$$
k_{\text {exp }}{ }^{\mathrm{eT}}=\frac{1}{\tau_{\text {betaine }}}-\frac{1}{\tau_{\text {ref }}} .
$$

The resultant eT rates are strongly solvent dependent. The sulfoalkylquinolinium betaines show a strong intramolecular quenching $\left(k_{\text {exp }}{ }^{\text {eT }} \sim 10^{9} \mathrm{~s}^{-1}\right)$ in acetonitrile, whereas in water $k_{\mathrm{exp}}{ }^{\mathrm{eT}}$ is about $10^{6} \mathrm{~s}^{-1}$, i.e. eT quenching does not affect fluorescence lifetimes. An entirely different (inverse) fluorescence decay behavior is found for the carboxyalkyl-quinolinium betaines. In acetonitrile no eT quenching $\left(k_{\exp }{ }^{\mathrm{eT}} \sim 10^{6} \mathrm{~s}^{-1}\right)$ is observed, whereas it is strong in water $\left(k_{\exp }{ }^{\mathrm{eT}} \sim 10^{9} \mathrm{~s}^{-1}\right)$ [26].

An explanation of this inverse behavior has been given using the theory of Bixon and Jortner (BJ) [26, 28]. For a recent review see [29]. Here non-adiabatic eT theory forms the basis for the description of the postulated photoinduced charge recombination kinetics. The BJ model describes the electron transfer along two perpendicular reaction coordinates, an intramolecular or "internal-sphere" mode and a collective solvent reorganization or "outersphere" mode, where the inner-sphere reorganization is treated quantum mechanically. Both outer-sphere and inner-sphere reorganization energy can be computed according to the classical theory of Marcus [7]. The outer-sphere reorganization energy $\lambda_{\mathrm{S}}$ was calculated from the approximate continuum model 
of Eq. (2) [7, 26],

$$
\lambda_{\mathrm{S}}=\frac{(\Delta \mathrm{e})^{2}}{4 \pi \varepsilon_{0}}\left(\frac{1}{2 r_{\mathrm{D}}}+\frac{1}{2 r_{\mathrm{A}}}-\frac{1}{R}\right)\left(\frac{1}{\varepsilon_{\mathrm{op}}}-\frac{1}{\varepsilon_{\mathrm{S}}}\right)
$$

where the reactant radii $\left(r_{\mathrm{D}}, r_{\mathrm{A}}\right)$ and the distance $R$ of the donor and acceptor centers are available from a semiempirical geometry analysis. The dielectric constants $\varepsilon$ were taken out of a recent monograph on PeT [1]. Eq. (2) is based on the assumption of an isotropic distribution of the solvent around the reactants. An empirical correction factor of 0.25 had to be applied to the value obtained from Eq. (2) which was interpreted as due to the close proximity of donor and acceptor in the intramolecular eT precursor complex [26].

The inner-sphere reorganization $\lambda_{\mathrm{v}}$ was assumed to occur in a single harmonic mode of effective frequency $v$, where the mode experiences an equilibrium shift upon eT, but the frequency does not change. Franck-Condon factors for vibronic transitions can then be computed analytically from the quantity $S=\lambda_{\mathrm{v}} / h v$ [28], which provides a measure of the horizontal shift of potential energy functions during $\mathrm{eT}$.

Free energies of PeT were computed according to Eq. (3)

$$
\Delta G^{\circ}=\Delta G^{\circ}\left(\mathrm{A}^{+} / \mathrm{A}\right)-\Delta G^{\circ}\left(\mathrm{D} / \mathrm{D}^{-}\right)-E_{0-0}-C
$$

from the reduction/oxidation potentials of the redox couples involved, the $0-0$ transition of the quinolinium ion absorption/emission and the coulombic stabilization $C$ of the intramolecular counter ions in the reactant state, respectively. The oxidation/reduction potentials were obtained theoretically from the differences in the heats of formation of the spatially separated ions (methylquinolinium, methylsulfonate and acetate ion) and their one-electron reduced or oxidized states, respectively, neglecting entropies, but including solvation using a self-consistent solvent reaction field [26]. The electrostatic energy $C$ of the PeT reactant state was calculated according to Suppan [30], accounting for the reduction of the macroscopic dielectric constant at close proximity of counter ions.

Thus, according to the model employed, the intramolecular electron transfer process is equivalent to a sum of vibronic transitions from Boltzmannweighted initial vibrational states to final states, governed by the respective Franck-Condon factors [28]. Along the outer-sphere coordinate, each vibronic transition is accompanied by a specific classical free energy of activation, due to the fact that vibronic energy gaps are modulated by thermal fluctuations of the solvent polarization. The most important vibronic pathways arise from a compromise between minimizing the free energy of activation and maximizing the Franck-Condon factor.

In the normal region of electron transfer (see below), i.e. $-\Delta G^{\circ}<\lambda$, with respect to the outer-sphere reorganization energy, transitions between vibrational ground levels of eT states provide the dominant pathway. In the inverted 
region however, i.e. $-\Delta G^{\circ}>\lambda$, transitions to vibrationally excited product states may lead to a decrease of the classical outer-sphere free energy of activation, and thus increase the eT rate as compared to the outer-sphere process alone, if Franck-Condon factors are favorable. As a result, an asymmetry is introduced into the eT rate as a function of driving force $-\Delta G^{\circ}$ (see below), while in the classical theory of Marcus it is a Gaussian.

The results obtained from the BJ theory [26] are shown together with the theoretical lifetimes $\tau_{\text {theo }}$ for the two model systems N-sulfoethyl- (4) and $\mathrm{N}$-carboxyethyl-quinolinium betaine (10) in Table 2. For more detailed information on how these parameters have been obtained, see [26].

The good agreement between theoretical and experimental fluorescence lifetimes shows that the intramolecular kinetics of deactivation can be rationalized in terms of the driving force $-\Delta G^{\circ}$ and the solvent reorganization parameter $\lambda_{\mathrm{S}}$, where $-\Delta G^{\circ}<\lambda$ describes the normal region, $-\Delta G^{\circ} \approx \lambda$ the activationless region and $-\Delta G^{\circ}>\lambda$ the inverted region. According to our theoretical considerations, the $\mathrm{C}-\mathrm{H} \cdots \mathrm{O}$ mode may operate as an "accepting mode" during eT quenching. The deviation of the theoretical and experimental decay times (Table 2) was assumed tolerable since a more precise determination of the $\Delta G^{\circ}$ value was not possible at that time [26].

Comparison of the $\Delta G^{\circ}$ values with the solvent reorganization parameter $\lambda_{\mathrm{S}}$ (Table 2) allows a classification of compound classes (dependent on the solvent) into different Marcus regions.

Compound (4) in water was predicted to be situated in the normal region of electron transfer, where the positive $\Delta G^{\circ}$ value prevents eT quenching in this solvent (endothermic eT). These results are assumed to be representative and transferable to the homologous compounds within classes $\mathrm{B}$ and $\mathrm{C}$, with longer alkyl chain lengths.

Table 2. According to the BJ model, thermodynamic and kinetic parameters of the compounds (4) and (10) were calculated for the solvents water and acetonitrile at $298 \mathrm{~K}$.

\begin{tabular}{|c|c|c|c|c|c|c|}
\hline Compound & Solvent & $\begin{array}{c}\lambda_{\mathrm{s}} \\
{[\mathrm{kJ} / \mathrm{mol}]}\end{array}$ & $\begin{array}{c}\Delta G^{\circ} \\
{[\mathrm{kJ} / \mathrm{mol}]}\end{array}$ & $\begin{array}{c}k^{\mathrm{eT}} \\
{\left[\mathrm{s}^{-1}\right]}\end{array}$ & $\begin{array}{l}\tau_{\text {theo }} \\
{[\mathrm{ns}]}\end{array}$ & $\begin{array}{c}\tau_{\mathrm{f}} \\
{[\mathrm{ns}]}\end{array}$ \\
\hline (4) & $\begin{array}{c}\mathrm{H}_{2} \mathrm{O} \\
\mathrm{CH}_{3} \mathrm{CN}\end{array}$ & $\begin{array}{l}34.7 \\
32.2\end{array}$ & $\begin{array}{l}+28.0 \\
-62.3\end{array}$ & $\begin{array}{l}2.3 \cdot 10^{5} \\
4.4 \cdot 10^{10}\end{array}$ & $\begin{array}{c}14.3 \\
0.02\end{array}$ & $\begin{array}{c}14.3 \\
0.31\end{array}$ \\
\hline (10) & $\begin{array}{c}\mathrm{H}_{2} \mathrm{O} \\
\mathrm{CH}_{3} \mathrm{CN}\end{array}$ & $\begin{array}{l}37.7 \\
34.7\end{array}$ & $\begin{array}{l}-107.5 \\
-125.9\end{array}$ & $\begin{array}{l}1.6 \cdot 10^{9} \\
4.5 \cdot 10^{6}\end{array}$ & $\begin{array}{r}0.6 \\
21.0\end{array}$ & $\begin{array}{l}0.47 \\
23.1\end{array}$ \\
\hline
\end{tabular}


An increase of the driving force $-\Delta G^{\circ}$ at almost constant $\lambda_{S}$ leads to an increase of the eT rate within the same class of compounds (class B). Since solvation is weaker in acetonitrile, the solvent reorganization energy is smaller than in water, while at the same time $\Delta G^{\circ}$ in acetonitrile becomes more negative (charge recombination). Therefore, compound (4) in acetonitrile was located (slightly) in the inverted region region $\left(-\Delta G^{\circ}>\lambda_{\mathrm{S}}\right)$ with respect to the outer-sphere process (Fig. 3).

Due to the substantially smaller oxidation potential of the carboxylate donor, compound (10) was predicted to lie in the inverted region in both solvents. The reason for this postulated behavior is easily rationalized in terms of a small solvent reorganization energy, due to the close proximity of intramolecular counter ions in the precursor complex of eT, while photoinduced charge recombination allows for large driving forces. However, only the carboxylato betaines in acetonitrile show a considerable decrease of the eT rate. For the latter system, this was explained by unfavorable Franck-Condon factors governing transitions to vibrationally highly excited product states, while these transitions may otherwise serve to reduce the effective driving force in the inverted region and thus to increase the rate by lowering the free energy of activation (compound (10) and homologous series of class D in water).

The organic compounds employed in our studies are regarded as unique model systems in the sense that they allow a detailed investigation of luminescence quenching by forward photoinduced charge recombination electron transfer. As stated above, the "inverted fluorescence behavior" of classes B and $\mathrm{D}$ can be understood as arising from the interplay of eT driving forces and

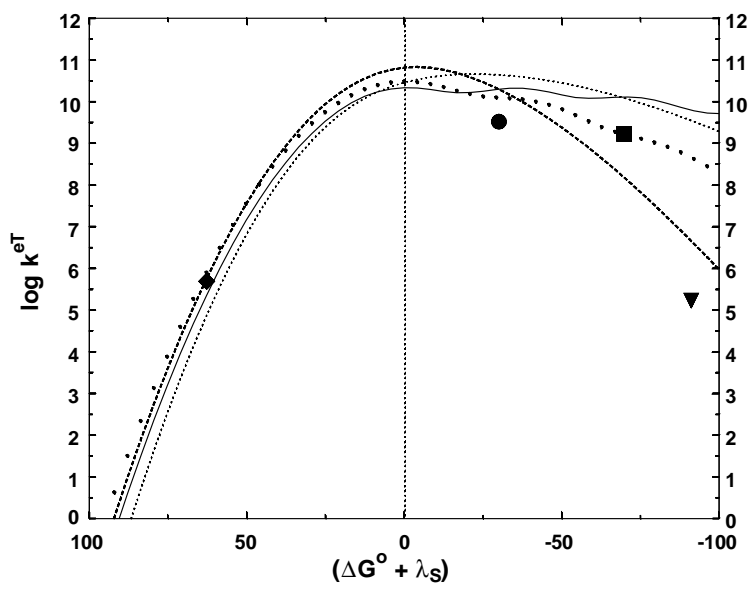

Fig. 3. Calculated eT rates for the compounds (4) and (10) as a function of the reaction free energy $\Delta G^{\circ}[\mathrm{KJ} / \mathrm{mol}]$, with constant $\lambda_{\mathrm{S}}[\mathrm{KJ} / \mathrm{mol}]$; (4) in $\mathrm{H}_{2} \mathrm{O}(-)$, (4) in $\mathrm{CH}_{3} \mathrm{CN}$ (...), (10) in $\mathrm{H}_{2} \mathrm{O}(\cdots)$, (10) in $\mathrm{CH}_{3} \mathrm{CN}(---)$; experimentally determined eT rates: (4) in $\mathrm{H}_{2} \mathrm{O}(\bullet),(4)$ in $\mathrm{CH}_{3} \mathrm{CN}(\bullet),(\mathbf{1 0})$ in $\mathrm{H}_{2} \mathrm{O}(\boldsymbol{\bullet}),(\mathbf{1 0})$ in $\mathrm{CH}_{3} \mathrm{CN}(\boldsymbol{\nabla})$. 
solvent reorganization energies, where both quantities (especially the driving force) are modulated by the polarity of the solvent and the driving force can be changed as usual by modifying the donor or acceptor.

In charge recombination electron transfer reactions the reactants carry opposite charges and therefore in our model systems tight precursor complexes are formed out of the intramolecular counter ions. This situation is expected to lead to relatively low outer-sphere reorganization energies, and may be compared to the role of the inverted region in nonradiative charge recombination for radical ions produced by forward charge separation fluorescence quenching [12]. Moreover, by decreasing the solvent polarity the driving force is increased while the solvent reorganization energy is decreased. Thus, the Marcus inverted region of electron transfer may be realized more easily by changing the solvent polarity in combination with a change of donor or acceptor.

To the best of our knowledge, our investigations of charge recombination luminescence quenching allowed for the first time the detection of the Marcus inverted region in conventional time-resolved fluorescence quenching experiments on forward charge recombination PeT [26]. In fact, electron transfer theory provides in our view the most natural way to rationalize the distinct and "inverse" fluorescence behavior of sulfonato- (class B) and carboxylatoquinolinium betaines (class D) in solvents of different polarity.

\section{Biexponential fluorescence behavior of class $D$}

The deactivation of class $\mathrm{D}((\mathbf{1 0})-(\mathbf{1 2}))$ in water shows a more complex behavior than the compounds of classes A, B and C already discussed in Sect. 2. Two fluorescence decay times with corresponding amplitudes (percentage) were observed (Table 3; cp. Table 1).

In order to explain this biexponential decay behavior of the class $\mathrm{D}$ betaines, we propose a simple acid-base equilibrium of the anionic headgroup $\mathrm{CO}_{2}{ }^{-}$. The two decay times can be assigned to the anionic or neutral form, respectively. To verify this acid/base model, we perform a titration of the betaine.

Table 3. Biexponential fluorescence decay behavior $\tau_{1 / 2}$ [ns] of N-carboxyalkyl-quinolinium betaines (class D) with different chain lengths in water $(T=298 \mathrm{~K})$. The corresponding amplitudes $\mathrm{A}_{1 / 2}$ in \% are given in parenthesis.

\begin{tabular}{|c|c|c|c|c|}
\hline \multicolumn{2}{|l|}{ Compound } & \multirow{2}{*}{$\frac{(10)}{2}$} & \multirow{2}{*}{$\frac{(11)}{3}$} & \multirow{2}{*}{$\frac{(12)}{4}$} \\
\hline Chain length $\boldsymbol{n}$ & & & & \\
\hline Decay time [ns] & $\begin{array}{l}\tau_{1} \\
\tau_{2}\end{array}$ & $\begin{array}{l}0.47(74 \%) \\
9.9(26 \%)\end{array}$ & $\begin{array}{r}3.3(61 \%) \\
11.4(39 \%)\end{array}$ & $\begin{array}{r}5.8(74 \%) \\
12.0(26 \%)\end{array}$ \\
\hline
\end{tabular}


It is important to select the titer that e.g. no heavy atomic effects (of $\mathrm{Cl}^{-}$in $\mathrm{HCl}$ ) or dissociation products may influence the fluorescence behavior.

As an inert titer trifluoroacetic acid (TFA) was used and added to a solution of N-carboxyethyl-quinolinium betaine $\left(2.0 \cdot 10^{-5} \mathrm{~mol} / \mathrm{l}\right)$ in water. The acid-base equilibrium was recorded by time-resolved spectroscopy. The titration curve is given in Fig. 4.

During the titration, the percentage of the amplitude changes by constant decay times. The amplitudes of the decay times show a significant behavior. At high concentration the contribution of the short decay time is small $(\sim 10 \%)$. Increasing the $\mathrm{pH}$ results in a continues increase of the amplitude of the short decay time. At $\mathrm{pH}$ values larger than 6.0 the short decay time dominates the fluorescence deactivation behavior. According to the fluorescence titration experiments the short decay time can be attributed to the anionic betaine with the deprotonated carboxy group. The long decay time which dominates in the low $\mathrm{pH}$ region therefore corresponds to the quinolinium dye with the protonated carboxy function. For the betaine investigated, we found a $\mathrm{p} K_{\mathrm{a}}$ value of $4.4\left(25^{\circ} \mathrm{C}\right)$.

In order to verify the assignment of the fluorescence decay times the carboxy side chain was esterified, preventing the molecular Coulomb interaction of the charged end groups (Table 4).

Comparing the fluorescence decay times of the betaine (10) and the ester (13) in the respective solvent (Table 4) suggests, that a neutral headgroup (through protonation or esterification) interacts only weak with the chromophore. Therefore the longer decay time of the protonated N-carboxyethylquinolinium betaine ( $9.9 \mathrm{~ns}$ ) should correspond to the appropriate time of the ester in water $(11.5 \mathrm{~ns})$. The short relaxation time $(0.5 \mathrm{~ns})$ of the betaine (10)

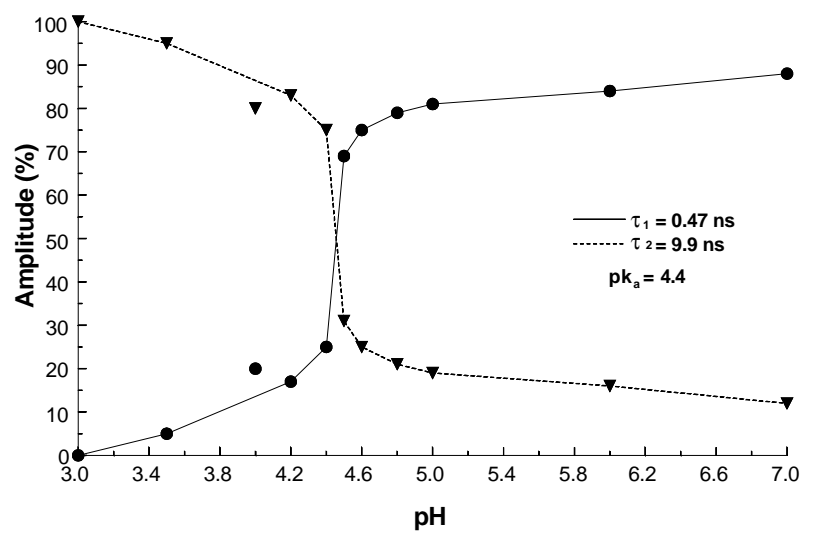

Fig. 4. Fluorescence spectroscopic titration of N-carboxyethyl-quinolinium betaine (10) with TFA. At constant decay times $\tau_{1}$ and $\tau_{2}$, the $\mathrm{pH}$ of the solution is plotted against the percentage of the amplitude of the decay time. 
Table 4. Fluorescence decay time of the $\mathrm{N}$-carboxyethyl-quinolinium betaine (10) in comparison with the quinolinium-methylacetate cation $(\mathbf{1 3})$ in water and acetonitrile $(T=298 \mathrm{~K})$. (The absorption and emission maxima show no significant changes $\left(\lambda_{\mathrm{abs}}=\right.$ $\left.316 \mathrm{~nm} ; \lambda_{\mathrm{em}}=\sim 410 \mathrm{~nm}\right)[21]$.)

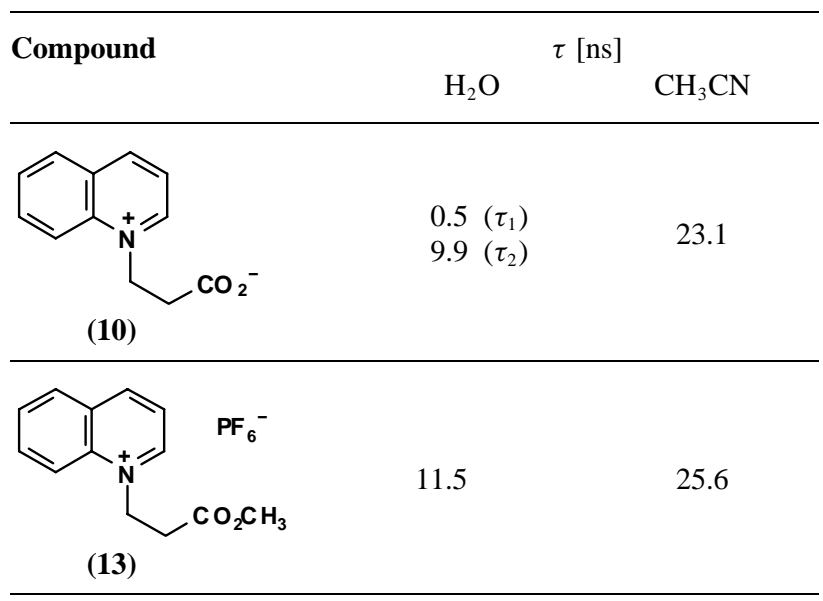

in water, is then a result of effective quenching of the deprotonated form. For the ester in acetonitrile a long decay time was observed (25.6 ns). This suggests a weak interaction of the headgroup as for the long decay time of the $\mathrm{N}$-carboxyethyl-quinolinium betaine (23.1 ns).

Summarizing, the long decay time can be assigned to the protonated form and the short decay time to the dissociated form of the betaine.

\section{Variation of the substitution pattern of the chromophore (class $\mathbf{E}$ and $\mathbf{F}$ )}

Beside the variation of donor type and alkyl chain length of the betaines, modification of the substitution pattern at the chromophore is another possible approach to probing the intramolecular interaction between the polar end groups of the flexible chain. Methyl substitution in different positions at the chromophore should sterically influence the proposed cyclic arrangement [23]. As can be seen from the fluorescence-spectroscopic measurements described for classes $\mathrm{B}$ and $\mathrm{C}$, an additional methyl substituent at $\mathrm{C} 2$ increases the decay time in the weakly interacting solvent acetonitrile (Table 1). Therefore, $\mathrm{N}$-sulfoethyl-quinolinium betaines were synthesized which bear a methyl substituent in different chromophore positions (class F) (Fig. 1). In addition to the singly methyl-substituted betaines, a compound with two methyl groups (at positions C2 and C8) (s. Table 5 (24)) was synthesized. Since the modifications at the aromatic system could in principle change the fluorescence behavior, the betaines were compared with the correspondingly substituted quinolin- 
Table 5. Fluorescence decay time $\tau_{\mathrm{f}}$ and the non-radiating contributions of the fluorescence deactivation $k_{\mathrm{nf}}$ of $\mathrm{N}$-ethyl-quinolinium and $\mathrm{N}$-sulfoethyl-quinolinium compounds (classes $\mathrm{E}$ and $\mathrm{F}$ ) with different positions of the methyl substituent $(R)$ in the solvent water and acetonitrile at $298 \mathrm{~K}$.

\begin{tabular}{|c|c|c|c|c|c|c|c|}
\hline \multirow[t]{2}{*}{ Compound } & \multirow{2}{*}{$\begin{array}{c}\text { Chain } \\
\text { length } \\
n\end{array}$} & \multirow{2}{*}{$\begin{array}{c}\text { Substitution } \\
\text { pattern } \\
\left(\mathbf{R}=\mathrm{CH}_{3}\right)\end{array}$} & \multirow[t]{2}{*}{$\begin{array}{c}\text { Compound } \\
\text { Nr. }\end{array}$} & \multicolumn{2}{|c|}{$\begin{array}{c}\text { Fl.-decay time } \\
\tau_{\mathrm{f}}[\mathrm{ns}]\end{array}$} & \multicolumn{2}{|c|}{$\begin{array}{c}\text { Velocity rate } \\
k_{\mathrm{nf}}\left[\mathrm{s}^{-1}\right]\end{array}$} \\
\hline & & & & $\mathrm{H}_{2} \mathrm{O}$ & $\mathrm{CH}_{3} \mathrm{CN}$ & $\mathrm{H}_{2} \mathrm{O}$ & $\mathrm{CH}_{3} \mathrm{CN}$ \\
\hline \multirow{6}{*}{ class E } & 2 & (2) & (14) & 15.1 & 14.4 & $3.4 \cdot 10^{7}$ & $3.4 \cdot 10^{7}$ \\
\hline & 2 & (3) & (15) & 14.1 & 14.8 & $3.6 \cdot 10^{7}$ & $3.0 \cdot 10^{7}$ \\
\hline & 2 & (4) & (16) & 14.3 & 15.0 & $3.3 \cdot 10^{7}$ & $3.3 \cdot 10^{7}$ \\
\hline & 2 & (6) & (17) & 21.0 & 27.6 & $2.5 \cdot 10^{7}$ & $1.4 \cdot 10^{7}$ \\
\hline & 2 & (8) & (18) & 40.8 & 43.5 & $1.1 \cdot 10^{7}$ & $7.3 \cdot 10^{6}$ \\
\hline & 2 & $(2)+(8)$ & (19) & 45.0 & 45.2 & $5.8 \cdot 10^{6}$ & $5.8 \cdot 10^{6}$ \\
\hline \multirow{6}{*}{ class $F$} & 2 & (2) & (7) & 13.6 & 3.6 & $4.2 \cdot 10^{7}$ & $2.6 \cdot 10^{8}$ \\
\hline & 2 & (3) & (20) & 15.4 & 0.54 & $3.4 \cdot 10^{7}$ & $2.0 \cdot 10^{9}$ \\
\hline & 2 & (4) & (21) & 18.0 & 0.22 & $3.1 \cdot 10^{7}$ & $5.0 \cdot 10^{9}$ \\
\hline & 2 & (6) & (22) & 20.5 & 1.1 & $2.9 \cdot 10^{7}$ & $9.1 \cdot 10^{8}$ \\
\hline & 2 & (8) & (23) & 41.7 & 43.2 & $1.1 \cdot 10^{7}$ & $5.5 \cdot 10^{6}$ \\
\hline & 2 & $(2)+(8)$ & (24) & 43.5 & 42.3 & $6.0 \cdot 10^{6}$ & $7.1 \cdot 10^{6}$ \\
\hline
\end{tabular}

ium cations, without polar headgroups (class E) (Fig. 1). For both compound classes the decay times were measured in water and acetonitrile (Table 5, Fig. 5).

\subsection{Fluorescence decay times}

A classification into a strong and a weak interacting solvent, derived from the characteristic fluorescence behavior of the compound classes $\mathrm{A}-\mathrm{C}$, as proposed in Sect. 2.1, is not possible here (s. Fig. 5).

\section{Class E:}

Comparing the decay times of the cationic class $\mathrm{E}$ in water and in acetonitrile (Fig. $5 x y$-plane), no significant difference is observed. Therefore the solvent has no influence on the deactivation behavior of the different compounds. The deactivation correlates with that of class $\mathrm{A}-\mathrm{C}$ in water (with and without headgroup; Table 1), which reveals no intramolecular quenching effect. Adding a methyl group in position $\mathrm{C} 2$ to $\mathrm{C} 4$ to the $\mathrm{N}$-ethyl-quinolinium cation, leads to a significant decrease of the decay times from $\sim 22$ ns to $\sim 15$ ns (Table 1 , Table 5). In markedly contrast a methyl group at position $\mathrm{C} 8$ raises the decay time to over $40 \mathrm{~ns}$ in both solvents.

\section{Class F:}

If a headgroup $\left(\mathrm{SO}_{3}{ }^{-}\right)$is attached to the cationic reference compounds of class $\mathrm{E}$ the fluorescence behavior is similar as observed for the classes B and $\mathrm{C}$ (Fig. 5). 


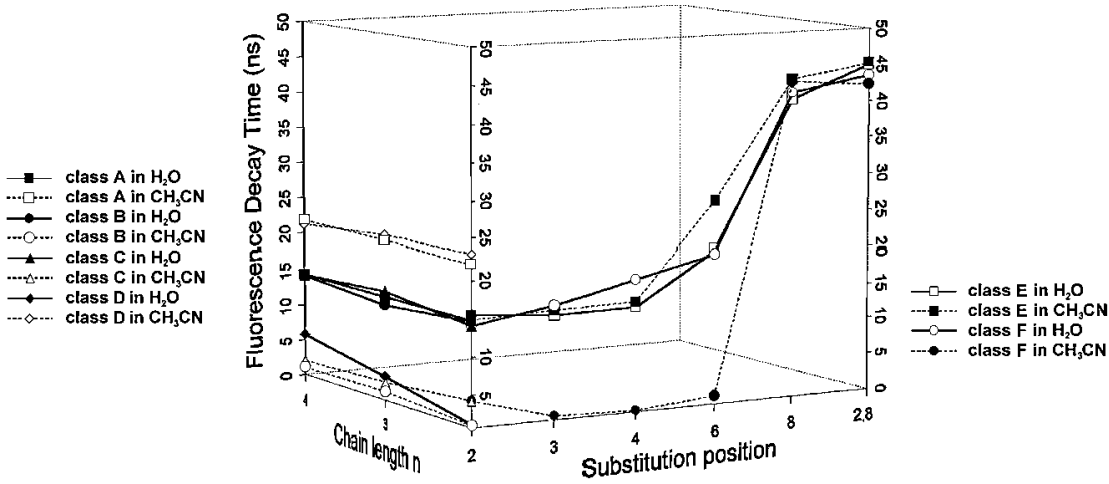

Fig. 5. The fluorescence decay times of the classes A, B, C and D (dependent on chain length) are projected on the $y z$-plane. Class $\mathrm{E}$ and $\mathrm{F}$ (dependent on the ring position of the methyl substituent) are projected on the $x y$-plane. All classes were measured in the solvents water (-) and acetonitrile (---) at $298 \mathrm{~K}$.

Category 1: In water the solvation characteristics of the betaines of class $\mathrm{F}$ are comparable to those of class $\mathrm{B}$ and $\mathrm{C}$ : The charged $\mathrm{SO}_{3}{ }^{-}$group is soluted and therefore the interaction to the aromatic system is weak (s. category 1 Sect. 2.1). If the methyl substituent is at position $\mathrm{C} 8$ (or at the positions $\mathrm{C} 2$ and C8), the decay time increases to over $40 \mathrm{~ns}$ as already described above (Fig. 5).

Category 2: Expect for methyl substitution at position $\mathrm{C} 8$ or $\mathrm{C} 2,8$, the fluorescence deactivation behavior of the compounds of class $\mathrm{F}$ in acetonitrile are comparable to those of class B and C. The intramolecular interaction of the charged end groups is not damped by the solvent and therefore the fluorescence deactivation is fast.

\subsection{Fluorescence rate constants}

To gain insights into a structure-fluorescence behavior relationship, we calculated the non-radiative component of the excited state deactivation. The non-radiative deactivation constant $k_{\mathrm{nf}}$ and the natural deactivation time $\tau_{0}$ of all classes are listed in Table 1, Table 5 (calculated according to Eq. (4)) and in literature [21], respectively.

$$
k_{\mathrm{nf}}=\frac{1}{\tau_{\mathrm{f}}}-k_{\mathrm{f} 0} \quad \text { and } \quad \tau_{0}=\frac{\tau_{\mathrm{f}}}{\phi_{\mathrm{f}}} .
$$

The rate constants of the non-radiative contribution $k_{\text {nf }}$ (ISC and/or eT) can be divided in two regions (according to Table 1, Fig. 6).

The first region is formed by compounds whose deactivation rate is relatively small $\left(\sim 3 \cdot 10^{7} \mathrm{~s}^{-1}\right)$. These substances are either cationic without a polar headgroup (class A in water and acetonitrile) or zwitterions in the solvent with 
a)

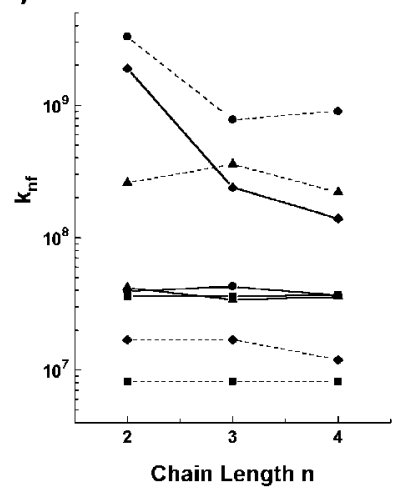

b)

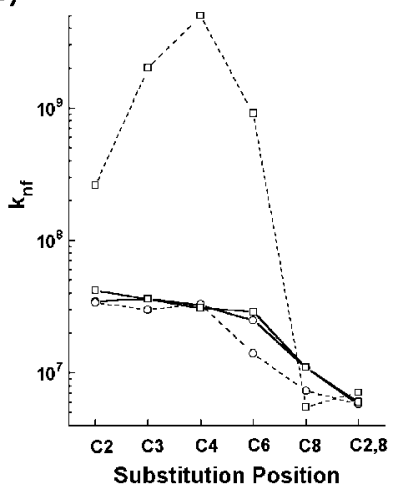

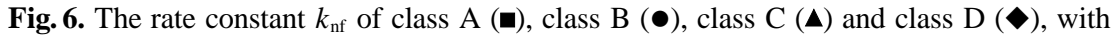
different alkyl chain lengths $\boldsymbol{n}$ (Fig. 6a) and of the class E (O) and class F ( $\square$ ) dependent on the position of the methyl substituent (Fig. 6b) in the solvents water (-) and acetonitrile $(---)$.

good solvation characteristics (classes $\mathrm{B}, \mathrm{C}$ in $\mathrm{H}_{2} \mathrm{O}$ and $\mathrm{D}$ in $\mathrm{CH}_{3} \mathrm{CN}$ ). In this environment the radiationless rate $\mathrm{knf}$ is determined exclusively by solvent collision processes.

Compounds with donor and acceptor not shielded by the solvent and therefore with strong intramolecular interactions (classes $\mathrm{B}, \mathrm{C}$ in $\mathrm{CH}_{3} \mathrm{CN}$ and $\mathrm{D}$ in $\mathrm{H}_{2} \mathrm{O}$ ) show increasing $k_{\mathrm{nf}}$ up to a factor of 100 to $1 \cdot 10^{9} \mathrm{~s}^{-1}$ (Fig. 6a). This amplification of the radiationless rate is due to intramolecular fluorescence quenching by the polar headgroup.

Comparing the methyl-substituted compounds (classes E, F) it is noteworthy to notice that one can observe a decrease of the radiationless rate for the class $\mathrm{E}$, both in water and in acetonitrile from $\sim 3 \cdot 10^{7} \mathrm{~s}^{-1}$ to $6 \cdot 10^{6} \mathrm{~s}^{-1}$. This also applies for class $\mathrm{F}$ in water (Fig. 6b). These results show the influence of the methyl position to the radiationless deactivation processes.

The analysis of the non-radiative rate constant $k_{\mathrm{nf}}$ supports the proposed deactivation by intramolecular interaction, which strongly depends on the solvent, the chain length, and the substitution pattern. Especially the latter correlation needs further analysis by structural and electrostatic aspects.

\subsection{Semiempirical calculations of classes $E$ and $F$}

To support the proposed mechanism of nonradiative deactivation via intramolecular interaction of the polar groups, conformational analyses were performed. The energetically favored conformer of each molecule was probed by the random incremental pulse search technique (RIPS) [31]. The energyoptimized MM2 [32] geometries served as starting points for a subsequent 
minimization using the PM3 Hamiltonian implemented in the MO-package VAMP $5.0[33,34]$.

The results obtained from semiempirical calculations (VAMP) for the lowest energy conformers are listed in Tables 6 and 7. The interacting molecular groups are indicated in parentheses and generalized by an $\mathrm{X}$ or marked by the appropriate digits $\left(2,8\right.$ and $2^{\prime}('=$ next $\mathrm{H} / \mathrm{C}$-atom of the methyl substituent at $\mathrm{C} 2$ or C8)) (Fig. 7).

The semiempirical calculations for all betaine compounds predict the formation of a cyclic intramolecular complex, with the anionic headgroup preferably oriented towards the $\mathrm{C} 2$ position (s. Sect. 2.2) [23,24]. Only when this position is shielded by a methyl substituent, a reorientation of the donor moiety takes place towards $\mathrm{C} 8$. If both positions, $\mathrm{C} 2$ and $\mathrm{C} 8$, are methylated (24), the orientation towards $\mathrm{C}^{\prime}$ is the one with the lowest energy, however with larger distances of interacting groups. According to earlier conformational ana-<smiles></smiles><smiles>Cc1cccc2ccc(C)[n+](CC(=O)O)c12</smiles>

Fig. 7. Nomenclature of the positions of interacting molecule fragments.

Table 6. Calculated bond lengths and distances [in $\AA$ ] between specific atoms in the classes $\mathrm{B}, \mathrm{C}$ and $\mathrm{F}$ compared to the average bond lengths $\varnothing \mathrm{C}-\mathrm{H}$ and $\varnothing \mathrm{S}-\mathrm{O}$ at the potential energy minimum of the conformation). ( $\mathbf{X})$ is the number of the interacting position of the atom specified before (s. Fig. 7).

\begin{tabular}{lcclllll}
\hline Compound & $\mathbf{O}_{i} \cdots \mathbf{H}(\mathbf{X})$ & $\mathbf{O}_{i} \cdots \mathbf{C}(\mathbf{X})$ & $\mathbf{C}_{\mathbf{2} / \mathbf{8}}-\mathbf{H}(\mathbf{X})$ & $\varnothing \mathbf{C}-\mathbf{H}$ & $\mathbf{S}-\mathbf{O}_{i}$ & $\varnothing \mathbf{S}-\mathbf{O}$ \\
\hline Class B & $\mathbf{( 4 )}$ & $1.660(2)$ & $2.810(2)$ & $1.180(2)$ & 1.098 & 1.540 & 1.471 \\
& $\mathbf{( 5 )}$ & $1.680(2)$ & $2.840(2)$ & $1.179(2)$ & 1.099 & 1.540 & 1.500 \\
& $\mathbf{( 6 )}$ & $1.680(2)$ & $2.850(2)$ & $1.180(2)$ & 1.098 & 1.540 & 1.497 \\
\hline Class C & $\mathbf{( 7 )}$ & $1.750(8)$ & $2.870(8)$ & $1.146(8)$ & 1.097 & 1.549 & 1.471 \\
& $\mathbf{( 8 )}$ & $1.740(8)$ & $2.880(8)$ & $1.148(8)$ & 1.098 & 1.559 & 1.581 \\
& $\mathbf{( 9 )}$ & $1.740(8)$ & $2.860(8)$ & $1.144(8)$ & 1.099 & 1.557 & 1.482 \\
\hline \multirow{2}{*}{ Class F } & $\mathbf{( 2 0})$ & $1.661(2)$ & $2.811(2)$ & $1.177(2)$ & 1.098 & 1.535 & 1.471 \\
& $\mathbf{( 2 1 )}$ & $1.662(2)$ & $2.811(2)$ & $1.175(2)$ & 1.099 & 1.535 & 1.471 \\
& $\mathbf{( 2 2}$ & $1.660(2)$ & $2.809(2)$ & $1.176(2)$ & 1.099 & 1.535 & 1.471 \\
& $\mathbf{( 2 3 )}$ & $1.670(2)$ & $2.813(2)$ & $1.176(2)$ & 1.097 & 1.535 & 1.472 \\
& $\mathbf{( 2 4 )}$ & $1.744\left(2^{\prime}\right)$ & $2.821\left(2^{\prime}\right)$ & $1.148\left(2^{\prime}\right)$ & 1.099 & 1.516 & 1.480 \\
& & & $3.403(2)$ & & & & \\
\hline
\end{tabular}


Table 7. Calculated bond orders between specific atoms in the classes B, C and F compared to the average bond orders $\varnothing \mathrm{C}-\mathrm{H}$ and $\varnothing \mathrm{S}-\mathrm{O}$ (at the potential energy minima of conformations). ( $\mathbf{X})$ is the number of the interacting position of the atom specified before (s. Fig. 7).

\begin{tabular}{lcclllll}
\hline Compound & $\mathbf{O}_{i} \cdots \mathbf{H}(\mathbf{X})$ & $\mathbf{O}_{i} \cdots \mathbf{C}(\mathbf{X})$ & $\mathbf{C}_{\mathbf{2} / \mathbf{8}}-\mathbf{H}(\mathbf{X})$ & $\varnothing \mathbf{C}-\mathbf{H}$ & $\mathbf{S}-\mathbf{O}_{i}$ & $\varnothing \mathbf{S}-\mathbf{O}$ \\
\hline Class B & $\mathbf{( 4 )}$ & $0.131(2)$ & $0.054(2)$ & $0.752(2)$ & 0.958 & 1.002 & 1.148 \\
& $\mathbf{( 5 )}$ & $0.119(2)$ & $0.051(2)$ & $0.764(2)$ & 0.958 & 1.011 & 1.146 \\
& $\mathbf{( 6 )}$ & $0.120(2)$ & $0.051(2)$ & $0.761(2)$ & 0.959 & 1.007 & 1.146 \\
\hline Class C & $\mathbf{( 7 )}$ & $0.066(8)$ & $0.036(8)$ & $0.835(8)$ & 0.961 & 0.994 & 1.146 \\
& $\mathbf{( 8 )}$ & $0.070(8)$ & $0.036(8)$ & $0.828(8)$ & 0.961 & 0.959 & 1.139 \\
& $\mathbf{( 9 )}$ & $0.062(8)$ & $0.030(8)$ & $0.837(8)$ & 0.961 & 0.945 & 1.137 \\
\hline Class F & $\mathbf{( 2 0}$ & $0.130(2)$ & $0.054(2)$ & $0.750(2)$ & 0.958 & 1.001 & 1.147 \\
& $\mathbf{( 2 1 )}$ & $0.129(2)$ & $0.053(2)$ & $0.755(2)$ & 0.945 & 1.003 & 1.147 \\
& $\mathbf{( 2 2 )}$ & $0.131(2)$ & $0.054(2)$ & $0.752(2)$ & 0.955 & 1.002 & 1.147 \\
& $\mathbf{( 2 3 )}$ & $0.127(2)$ & $0.054(2)$ & $0.755(2)$ & 0.948 & 1.007 & 1.145 \\
& $\mathbf{( 2 4 )}$ & $0.072\left(2^{\prime}\right)$ & $0.033\left(2^{\prime}\right)$ & $0.835\left(2^{\prime}\right)$ & $0.968\left(2^{\prime}\right)$ & 1.045 & 1.128 \\
\hline
\end{tabular}

lyses of class A, the compounds of class $\mathrm{E}$ show no preferred orientation of the unpolar side chain $[23,24]$.

The intramolecular donor-acceptor interaction may be characterized by bond distances and bond orders of the atoms involved. It becomes obvious from Table 6 that the interacting $\mathrm{C}-\mathrm{H}(\mathrm{X})$ and $\mathrm{S}-\mathrm{O}_{i}$ bonds of all classes are stretched, as compared to the average value of the remaining $\mathrm{C}-\mathrm{H}$ and $\mathrm{S}-\mathrm{O}$ bonds in the molecule. The bond orders basically reflect the same tendencies. If an interaction occurs between the polar groups, the electron densities of the bonds involved $\left(\mathrm{C}_{X}-\mathrm{H}\right.$ or $\left.\mathrm{S}-\mathrm{O}_{i}\right)$ decrease by electron delocalisation as compared to the average values. In parallel, the electron density between interacting donor and acceptor atoms $\left(\mathrm{O}_{i} \cdots \mathrm{H}\right.$ or $\left.\mathrm{O}_{i} \cdots \mathrm{C}\right)$ increases.

However, the efficiency of fluorescence quenching will not exclusively depend upon the distances of the ionic donor and acceptor groups, rather it is expected that the relative orientation of donor and acceptor orbitals will be of crucial importance (Table 8) [23, 25].

The decisive orbital interactions may be described by the angle $\beta$ between the $\mathrm{S}-\mathrm{O}_{i}$ bond and the aromatic plane (defining the $x y$-plane), as depicted in Fig. 8, where the $\pi$-electrons are oriented in the $z$-direction.

If a favorably small angle $\beta\left(\mathrm{S}-\mathrm{O}_{i}\right.$ bond is situated in the $x y$-plane) will be increased, the interaction $\mathrm{O}-p_{z} \leftrightarrow \pi$ assumed decisive for the quenching process, will be reduced. A comparison of the angle $\beta$ with the decay times does, however, not provide a complete picture.

In order to give a complete account of the electronic donor-acceptor interaction, the geometrical orientation of the donor group relative to the aromatic 
Table 8. Geometrical values (angles in ${ }^{\circ}$ ) and predicted orbital coefficients for classes B, $\mathrm{C}$ and $\mathrm{F}$, compared to the decay times $\tau_{\mathrm{f}}(\overline{\mathrm{ns}})$ in acetonitrile.

\begin{tabular}{lccccc}
\hline Compound & $\begin{array}{c}\boldsymbol{\tau}_{\mathbf{f}}[\mathbf{n s}] \\
\left(\mathbf{C H}_{\mathbf{3}} \mathbf{C N}\right)\end{array}$ & angle $\boldsymbol{\beta}$ & $\begin{array}{c}\mathbf{O}-\boldsymbol{p}_{z}{ }^{2} \\
{[\%]}\end{array}$ & $\begin{array}{c}\boldsymbol{p}_{z}{ }^{2} /\left(\boldsymbol{s}^{2}+\boldsymbol{p}_{\boldsymbol{x}}{ }^{2}+\boldsymbol{p}_{\boldsymbol{y}}{ }^{2}+\boldsymbol{p}_{z}{ }^{2}\right) \\
{[\%]}\end{array}$ \\
\hline Class B & $\mathbf{( 4 )}$ & 0.3 & 0.3 & 94.1 & 95.9 \\
& $\mathbf{( 5 )}$ & 1.2 & 21.0 & 74.0 & 84.6 \\
& $\mathbf{( 6 )}$ & 1.0 & 9.4 & 86.5 & 93.3 \\
\hline Class C & $\mathbf{( 7 )}$ & 3.6 & 53.1 & 13.0 & 20.7 \\
& $\mathbf{( 8 )}$ & 2.5 & 55.8 & 21.2 & 30.2 \\
& $\mathbf{( 9 )}$ & 2.0 & 26.1 & 46.2 & 73.9 \\
\hline \multirow{2}{*}{ Class F } & $\mathbf{( 2 0})$ & 0.5 & 0.98 & 70.3 & 96.3 \\
& $\mathbf{( 2 1 )}$ & 0.2 & 0.25 & 70.0 & 96.4 \\
& $\mathbf{( 2 2 )}$ & 1.1 & 0.50 & 70.3 & 96.5 \\
& $\mathbf{( 2 3 )}$ & 43.2 & 4.72 & 69.5 & 41.0 \\
& $\mathbf{( 2 4 )}$ & 42.3 & 19.2 & 25.9 & \\
\hline
\end{tabular}
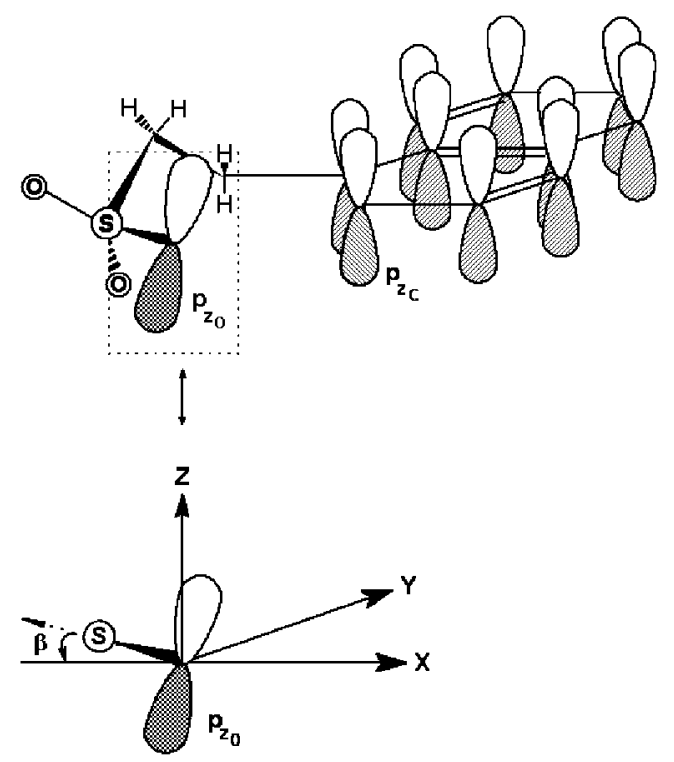

Fig. 8. Labeling of the characteristic angle and orbitals.

plane, as described by the angle $\beta$, is to be supplemented by the $\mathrm{O}-p_{z}$ coefficient of the donor HOMO (Table 8), which provides optimal overlap with the aromatic $\pi$-system or, more specifically, with the $\pi$-HOMO of the acceptor. The latter orbital is the dominant singly occupied MO (SOMO) in the first 
excited singlet state of the quinolinium chromophore, and therefore bears an 'electron hole' into which a donor electron may be injected, thereby quenching the fluorescent state.

The sum of squares of the individual oxygen atomic orbital coefficients $\left(s^{2}+p_{x}{ }^{2}+p_{y}{ }^{2}+p_{z}{ }^{2}\right)$ is comparable for all compounds $(\sim 70 \%)$, while the $p_{z}$-contribution is regarded to be decisive in controlling the magnitude of electronic interaction (Table 8, last column). But the compound with the highest $p_{z}{ }^{2} /\left(s^{2}+p_{x}{ }^{2}+p_{y}{ }^{2}+p_{z}{ }^{2}\right)$ ratio is not the one with the shortest decay time. Only the combination of geometrical (angle $\beta$ ) and electronical aspects $\left(\mathrm{O}-p_{z}\right)$ gives a satisfactory correlation with the observed fluorescence decay times. Using these arguments, intramolecular complexes with a relatively small angle $\beta$ and a high percentage of $\mathrm{O}-p_{z}{ }^{2}$ should provide an optimal donor-acceptor interaction responsible for non-radiative deactivation via $\mathrm{eT}$, as realized e.g. for compound (21) (s. Table 8).

Despite the good correlation of experimental data and theoretically obtained molecular parameters, it should not be ignored that the approach described relies on a static picture, where all calculations have been done for the respective conformation of lowest energy. Beyond this static view of molecular electronic interactions, thermal fluctuations driving transitions between different conformational substates of the cyclic donor-acceptor complexes have to be taken into account. We note here, that the Arrhenius activation energies obtained from the temperature dependence of the non-radiative decay of class B compounds in acetonitrile [23], may be related to the electronic interactions evaluated for the respective 'static' complexes. Typically, the largest activation energy is observed for the model compound with the smallest orbital overlap. This correlation allows to at least partially interpret the underlying thermally activated process to give access to conformational states associated with larger electronic donor-acceptor interaction.

\section{Conclusion}

The intramolecular fluorescence quenching of zwitterionic quinolinium dyes (quinolinium betaines) has been investigated by means of time-resolved fluorescence spectroscopy. Experimental observations may consistently be rationalized in terms of an intramolecular photoinduced charge recombination (electron transfer) process, where the quinolinium fluorophore acts as an electron acceptor and the intramolecular counter ion as the donor. Semiempirical quantum chemical methods and non-adiabatic electron transfer rate theory are employed to elucidate the essential molecular and solvent parameters governing the rates and quantum yields of fluorescence quenching and to support the interpretation of experimental results.

Besides the specific thermodynamic driving force dependence of rates according to classical Marcus theory, non-adiabatic electron transfer processes 
are controlled by the electronic interaction (electron exchange matrix element) between electron donor and acceptor. A combination of molecular mechanics and semiempirical molecular orbital methodology supports the idea of intramolecular complex formation in the quinolinium betaines, where donor and acceptor are held in close proximity via coulombic forces. These complexes, formed in the electronic ground state prior to optical excitation and stable in the locally excited singlet state, may act as suitable precursors for fluorescence quenching via electron transfer. The dependence of fluorescence quenching rates, obtained for quinolinium- and quinaldinium-betaines, upon the length of the alkyl chain linking donor and acceptor may be rationalized in terms of the electron donor-acceptor interaction (orbital overlap) controlled by the most stable conformational states of the intramolecular complex. Moreover, the specific temperature dependence of quenching rates, i.e. the Arrhenius activation energy, at a given alkyl chain length may be related to the thermally activated conformational dynamics of the alkyl-linker, providing access to states of stronger donor-acceptor interaction.

In a series of model compounds, the degree of electronic interaction could be modified by sterically shielding the quinolinium chromophore from a close approach of the donor moiety, providing evidence for an electronically nonadiabatic quenching process. In order to evaluate the effect of shielding upon the postulated intramolecular electron transfer, fluorescence lifetimes of betaines have been measured against the decay times of respective quinolinium compounds without a donor moiety. For the most stable conformations of sterically shielded and non-shielded complexes, electron donor-acceptor interactions have been characterized by semiempirical quantum chemistry in terms of the orbital overlap between the donor HOMO and the dominant lowest singly occupied MO of the first excited quinolinium $\pi, \pi^{*}$ singlet state.

Apart from the effect of steric hindrance upon fluorescence decay times, the striking solvent and thermodynamic driving force dependence of experimentally determined intramolecular quenching rates provide further evidence for an underlying photoinduced electron transfer mechanism. Sulfonato-betaines, at a given alkyl-linker chain length, exhibit strong intramolecular fluorescence quenching in acetonitrile, while no quenching is observed in water as the more polar solvent. In the framework of classical Marcus theory, this behavior may be explained via the combined effect of an increase in the driving force $\left(-\Delta G^{\circ}\right)$ and a decrease of solvent reorganization energy for a photoinduced charge recombination, when the polarity of solvent is decreased (normal region behavior). The validity of the electron transfer concept has been probed by further increasing the intrinsic eT driving force via change of the donor. And in fact, the carboxylato-betaines bearing a stronger electron donor show a distinct and 'inverse' fluorescence decay in the two solvents water and acetonitrile, as compared to the sulfonato compounds, i.e. strong quenching in water, no quenching in acetonitrile (inverted region behavior). As shown in theoretical studies combining semiempirical quantum chemistry and non-adiabatic eT rate 
theory, electron transfer theory provides a consistent and unifying framework for the qualitative as well as the quantitative interpretation of the fluorescence quenching properties of sulfonato- and carboxylato-quinolinium betaines.

While spectroscopic information on the postulated charge recombined intermediate biradical, formed as a result of photoinduced electron transfer in our model quinolinium betaines, is still lacking, the fluorescence properties gathered so far and the accompanying theoretical approaches strongly support the assumed quenching mechanism. On the basis of results obtained by conventional ns-fluorescence spectroscopy, experiments with increased timeresolution (ps or fs pump/probe techniques) should be able to provide more in depth insights into the photoinduced electronic/nuclear dynamics and intermediates of these interesting quasi-supramolecular photochemical model systems.

\section{Experimental section}

The following devices were used for analytical and spectroscopical investigations. All solvents and chemicals were of reagent or spectral grade quality, purchased commercially and used without further purification except as mentioned.

Melting points were obtained on a Kofler-Microheater and are uncorrected. The purification of the products was managed on a Bio-Rad 1706 HPLC with UV/VIS-Monitor and a reversed phase column. NMR Spectroscopy was performed on a Bruker AC 250 spectrometer operating at $250-\mathrm{MHz}$ for ${ }^{1} \mathrm{H}-\mathrm{NMR}$ and at $63 \mathrm{MHz}$ for ${ }^{13} \mathrm{C}-\mathrm{NMR}$. The spectra were recorded using $\mathrm{CDCl}_{3}$ and $\mathrm{D}_{2} \mathrm{O}$ as solvent, respectively. The data are presented as follows: chemical shift $f$ (multiplicity, $J \mathrm{~Hz}$, integration). The elemental microanalyses were performed by the analytical laboratory of the institute of the Inorganic Chemistry, University of Würzburg with a Carlo-Erba Element Analyzer 1106.

Absorption and fluorescence spectra were recorded on a Hitachi U 3210 VIS/UV spectrometer and a SLM Aminco-Bowman Spectrometer Series 2, respectively. The concentration of the substances was $10^{-5} \mathrm{~mol} / \mathrm{l}$.

Time and wavelength resolved emission transients were obtained using a commercial equipment SPC-spectrometer (Edinburgh Instruments, model 199S) with excitation and emission wavelengths at $337 \mathrm{~nm}$ and $420 \mathrm{~nm}$ respectively (with nanosecond time resolution). Data were analyzed using least-squares iterative reconvolution technique $\left(\chi^{2}<1.2\right)$ as described elsewhere [35-39].

\section{General synthesis procedures [21]:}

$N$-alkyl-quinolinium cations (class $\boldsymbol{A}$ ) and methyl-substituted $N$-ethyl-quinolinium cations (class $\boldsymbol{E})$ :

An equimolare solution of quinoline or 2-methylquinoline, respectively and ethyliodide was simply heated under reflux until crystallization. After cooling 
to RT the precipitate was filtered off and recrystallized from ethanol in a refrigerator at $-10^{\circ} \mathrm{C}$. The solid product was filtered off, dried, soluted in less water and recrystallized by a solution of ammonium hexafluorophosphate in ethanol to form the $\mathrm{N}$-alkyl-quinolinium hexafluorophosphates [40].

$N$-sulfoalkyl-quinolinium betaines (class B) and $N$-sulfoalkyl-quinaldinium betaines (class $\boldsymbol{C}$ ) [21]:

The nitrogen of the quinoline compounds was quaternized by a 2-sulfoetyhl group in reaction of 2-chloroethanesulfonyl chloride in acetic acid according to $[41,42]$. To obtain the propyl- or butyl-betaine derivatives, the heterocyclic compounds are treated with 1,3-propane sultone or 1,4-butane sultone, respectively, based on the procedure described by Wolfbeis and Urbano [43, 44].

$N$-carboxyalkyl-quinolinium betaines (class $\boldsymbol{D}$ ) [45-47]:

To obtain these carboxyalky betaines, a solution of quinoline (1.2 eq) is heated with the haloalkaneionic acid (e.g. 3-chloropropionic acid for the 1-(2'-carboxyethyl)-quinolinium-betaine) (1.5 eq) under reflux until crystallization. After cooling to RT the precipitate was filtered off and recrystallized in ethanol in a refrigerator at $-10^{\circ} \mathrm{C}$. The solid product was filtered off, recrystallized in ethanol and dried under vacuum.

Methyl-substituted N-sulfoethyl-quinolinium betaines (class $\boldsymbol{F}$ ) [41-44, 48-53]:

To synthesize these 2-sulfoethyl-betaines, the methyl substituted quinoline (1.2 eq) is treated with 2-chloroethanesulfonyl chloride (1.0 eq) in acetic acid $(10 \mathrm{ml} / \mathrm{eq}$ quinoline). The solution was heated under reflux until crystallization. After cooling to RT the precipitate was filtered off and recrystallized in ethanol in a refrigerator at $-10^{\circ} \mathrm{C}$. The solid product was filtered off, dried, recrystallized in ethanol and dried under vacuum.

1-(2-Carbmethoxyethyl)-quinolinium-hexafluorophosphate (13) [54]

A solution of quinoline $(9.2 \mathrm{~g}, 71.2 \mathrm{mmol})$ and 3-bromopropionic acid ethyl ester $(13.07 \mathrm{~g}, 78.27 \mathrm{mmol})$ was refluxed in $10 \mathrm{ml}$ ethanol for 4 hours. After cooling, the red solution was filtered and concentrated until crystallization. The product is treated first with $10 \mathrm{ml}$ acetone and then with water $(50 \mathrm{ml})$. The suspension is filtered and the water is extracted by distillation. The isolated bromide salt is recrystallized from ethylacetate/ether $(1: 1)$ and resalted in water with ammonium hexafluorophosphate at room temperature. After filtering and washing with less water, the product is dried under vacuum to give white crystals (92 yield). ${ }^{1} \mathrm{H}-\mathrm{NMR}\left(\mathrm{D}_{2} \mathrm{O}\right): \delta=3.25(\mathrm{t}, J=6.58 \mathrm{~Hz}$, $\left.2 \mathrm{H}, \mathrm{CH}_{2} \underline{\mathrm{H}}_{2} \mathrm{CO}_{2} \mathrm{CH}_{3}\right), 3.64\left(\mathrm{~s}, 3 \mathrm{H}, \mathrm{O}-\mathrm{C}_{3}\right), 5.33(\mathrm{t}, J=6.58 \mathrm{~Hz}, 2 \mathrm{H}$, $\left.\mathrm{N}^{+} \underline{\mathrm{CH}}_{2} \mathrm{CH}_{2}\right), 7.98(\mathrm{~m}, 1 \mathrm{H}, 6-H), 8.14(\mathrm{t}, J=8.56 \mathrm{~Hz}, 1 \mathrm{H}, 3-H), 8.23(\mathrm{dt}$, $J(6,7,8)=7.68 \mathrm{~Hz}, J(5,7)=1.2 \mathrm{~Hz}, 1 \mathrm{H}, 7-H), 8.34(\mathrm{~d}, J=8.71 \mathrm{~Hz}, 1 \mathrm{H}$, $5-H), 8.38(\mathrm{~d}, J=8.90 \mathrm{~Hz}, 1 \mathrm{H}, 4-H), 9.10(\mathrm{~d}, J=8.88 \mathrm{~Hz}, 1 \mathrm{H}, 8-H), 9.32$ $(\mathrm{dd}, \quad J(2,3)=7.45 \mathrm{~Hz}, \quad J(2,4)=1.2 \mathrm{~Hz}, \quad 1 \mathrm{H}, 2-H)$. Anal. Calcd for $\mathrm{C}_{13} \mathrm{H}_{14} \mathrm{~F}_{6} \mathrm{NO}_{2} \mathrm{P}$ (361.4): C, 43.23; H, 3.91; N, 3.88. Found: C, 43.30; H, 3.75; $\mathrm{N}, 3.92$. 


\section{1-Ethyl-2-methyl-quinolinium-hexafluorophosphate (14)}

white crystals; $\mathrm{mp} 118{ }^{\circ} \mathrm{C}(15 \%$ yield $) ;{ }^{1} \mathrm{H}-\mathrm{NMR}\left(250 \mathrm{MHz}, \mathrm{CDCl}_{3}\right): \delta=1.79$ (t, $\left.J=7.3 \mathrm{~Hz}, 3 \mathrm{H}, \mathrm{CH}_{2} \mathrm{C}_{3}\right), 3.13\left(\mathrm{~s}, 3 \mathrm{H}\right.$, aromat- $\left.\underline{C}_{3}\right), 5.14(\mathrm{q}, J=7.3 \mathrm{~Hz}$, $\left.2 \mathrm{H}, \mathrm{N}^{+} \mathrm{C}_{2} \mathrm{CH}_{3}\right), 7.55(\mathrm{t}, J=7.5 \mathrm{~Hz}, 1 \mathrm{H}, 6-H), 7.72(\mathrm{t}, J=9.0 \mathrm{~Hz}, 1 \mathrm{H}$, $7-H), 7.90(\mathrm{~d}, J=9.0 \mathrm{~Hz}, 1 \mathrm{H}, 5-H), 7.96(\mathrm{~d}, J=9.2 \mathrm{~Hz}, 1 \mathrm{H}, 8-H), 8.58$ $(\mathrm{d}, J=9.0 \mathrm{~Hz}, 1 \mathrm{H}, 3-H), 8.87(\mathrm{~d}, J=9.0 \mathrm{~Hz}, 1 \mathrm{H}, 4-H) ;{ }^{13} \mathrm{C}-\mathrm{NMR}(63 \mathrm{MHz}$, $\mathrm{D}_{2} \mathrm{O}$ ): $\delta=15.5$ (13-C), 22.4 (11-C), 47.3 (12-C), 118.8 (6-C), 125.5 (3-C), 128.3 (5-C), 129.0 (7-C), 130.6 (9-C), 135.3 (8-C), 138.1 (10-C), 145.5 (4-C), 160.4 (2-C). Anal. Calcd for $\mathrm{C}_{12} \mathrm{H}_{14} \mathrm{NPF}_{6}$ (317.1): C, 45.45; H, 4.45; N, 4.42. Found: C, 44.98; H, 4.40; N, 4.38 .

\section{1-Ethyl-3-methyl-quinolinium-hexafluorophosphate (15)}

white-pink crystals; mp $116{ }^{\circ} \mathrm{C}$ (78\% yield); ${ }^{1} \mathrm{H}-\mathrm{NMR}\left(250 \mathrm{MHz}, \mathrm{CDCl}_{3}\right)$ : $\delta=1.79\left(\mathrm{t}, J=7.3 \mathrm{~Hz}, 3 \mathrm{H}, \mathrm{CH}_{2} \mathrm{C}_{3}\right), 2.77\left(\mathrm{~s}, 3 \mathrm{H}\right.$, Aromat- $\left.\underline{H}_{3}\right), 5.11(\mathrm{q}, J=$ $\left.7.3 \mathrm{~Hz}, 2 \mathrm{H}, \mathrm{N}^{+} \underline{\mathrm{C}}_{2} \mathrm{CH}_{3}\right), 7.63(\mathrm{dt}, J(5,6,7)=6.9 \mathrm{~Hz}, J(6,8)=1.1 \mathrm{~Hz}, 1 \mathrm{H}$, 6- $H), 7.77(\mathrm{dt}, J(6,7,8)=7.0 \mathrm{~Hz}, J(5,7)=1.5 \mathrm{~Hz}, 1 \mathrm{H}, 7-H), 7.86(\mathrm{~d}, J=$ $8.1 \mathrm{~Hz}, 1 \mathrm{H}, 5-H), 8.14(\mathrm{~d}, J=7.6 \mathrm{~Hz}, 1 \mathrm{H}, 8-H), 8.15(\mathrm{~d}, J=2.0 \mathrm{~Hz}, 1 \mathrm{H}, 4-H)$, $8.85(\mathrm{~d}, J=2.0 \mathrm{~Hz}, 1 \mathrm{H}, 2-H) ;{ }^{13} \mathrm{C}-\mathrm{NMR}\left(63 \mathrm{MHz}, \mathrm{D}_{2} \mathrm{O}\right): \delta=15.5(13-\mathrm{C})$, 18.7 (11-C), 52.7 (12-C), 118.5 (5-C), 128.9 (10-C), 129.3 (6-C), 129.7 (8-C), 131.8 (3-C), 135.0 (7-C), 135.6 (9-C), 146.2 (4-C), 151.4 (2-C). Anal. Calcd for $\mathrm{C}_{12} \mathrm{H}_{14} \mathrm{NPF}_{6}$ (317.1): C, 45.45; H, 4.45; N, 4.42. Found: C, 45.51; H, 4.46; $\mathrm{N}, 4.43$.

\section{1-Ethyl-4-methyl-quinolinium-hexafluorophosphate (16)}

yellow crystals; mp $122^{\circ} \mathrm{C}$ (84\% yield); ${ }^{1} \mathrm{H}-\mathrm{NMR}\left(250 \mathrm{MHz}, \mathrm{CDCl}_{3}\right.$ ): $\delta=1.69\left(\mathrm{t}, J=7.3 \mathrm{~Hz}, 3 \mathrm{H}, \mathrm{CH}_{2} \mathrm{C}_{3}\right), 2.95\left(\mathrm{~s}, 3 \mathrm{H}\right.$, Aromat- $\left.\underline{\mathrm{C}}_{3}\right), 4.99$ $\left(\mathrm{q}, J=7.3 \mathrm{~Hz}, 2 \mathrm{H}, \mathrm{N}^{+} \mathrm{CH}_{2} \mathrm{CH}_{3}\right), 7.83(\mathrm{~d}, J=6.1 \mathrm{~Hz}, 1 \mathrm{H}, 3-H), 7.91$ $(\mathrm{dt}, J(5,6,7)=8.2 \mathrm{~Hz}, J(6,8)=1.0 \mathrm{~Hz}, 1 \mathrm{H}, 6-H), 8.12(\mathrm{dt}, J(6,7,8)=$ $8.1 \mathrm{~Hz}, J(5,7)=1.1 \mathrm{~Hz}, 1 \mathrm{H}, 7-H), 8.24(\mathrm{~d}, J=9.1 \mathrm{~Hz}, 1 \mathrm{H}, 5-H), 8.31$ $(\mathrm{dd}, J(7,8)=8.1 \mathrm{~Hz}, J(6,8)=1.0 \mathrm{~Hz}, 1 \mathrm{H}, 8-H), 9.08(\mathrm{~d}, J=6.1 \mathrm{~Hz}, 1 \mathrm{H}$, 2-H). ${ }^{13} \mathrm{C}-\mathrm{NMR}\left(63 \mathrm{MHz}, \mathrm{D}_{2} \mathrm{O}\right): \delta=16.3$ (13-C), 20.6 (11-C), 52.3 (12-C), 118.8 (5-C), 122.9 (3-C), 127.8 (6-C), 128.6 ( 10-C), 129.8 (8-C), 135.3 (7-C), 136.5 (9-C), 148.4 (2-C), 159.9 (4-C). Anal. Calcd for $\mathrm{C}_{12} \mathrm{H}_{14} \mathrm{NPF}_{6}$ (317.1): C, 45.45; H, 4.45; N, 4.42. Found: C, 45.41; H, 4.44; N, 4.42.

\section{1-Ethyl-6-methyl-quinolinium-hexafluorophosphate (17)}

white crystals; $\mathrm{mp} 124{ }^{\circ} \mathrm{C}(70 \%$ yield $) ;{ }^{1} \mathrm{H}-\mathrm{NMR}\left(250 \mathrm{MHz}, \mathrm{CDCl}_{3}\right): \delta=1.60$ $\left(\mathrm{t}, J=7.3 \mathrm{~Hz}, 2 \mathrm{H}, \mathrm{CH}_{2} \mathrm{C}_{3}\right), 2.47\left(\mathrm{~s}, 3 \mathrm{H}\right.$, Aromat- $\left.\underline{H}_{3}\right), 5.27(\mathrm{q}, J=7.3 \mathrm{~Hz}$, $\left.2 \mathrm{H}, \mathrm{N}^{+} \mathrm{CH}_{2} \mathrm{CH}_{3}\right), 7.88(\mathrm{~d}, \mathrm{~d} J(7,8)=9.1 \mathrm{~Hz}, J(5,7)=1.9 \mathrm{~Hz}, 1 \mathrm{H}, 7-H), 7.93$ $(\mathrm{d}, J(5,7)=2.3 \mathrm{~Hz}, 1 \mathrm{H}, 5-H), 7.96(\mathrm{t}, J=5.8 \mathrm{~Hz}, 1 \mathrm{H}, 3-H), 8.24(\mathrm{~d}, J=$ $9.1 \mathrm{~Hz}, 1 \mathrm{H}, 4-H), 8.87(\mathrm{~d}, J=8.4 \mathrm{~Hz}, 1 \mathrm{H}, 8-H), 10.17(\mathrm{dd}, J(2,3)=4.7 \mathrm{~Hz}$, $J(2,4)=1.2 \mathrm{~Hz}, 1 \mathrm{H}, 2-H) \cdot{ }^{13} \mathrm{C}-\mathrm{NMR}\left(63 \mathrm{MHz}, \mathrm{CDCl}_{3}\right): \delta=16.3(13-\mathrm{C}), 21.7$ (11-C), 53.9 (12-C), 118.4 (5-C), 122.8 (3-C), 129.9 (7-C), 130.4 (10-C), 136.3 
(8-C), 138.6 (6-C), 141.4 (9-C), 146.6 (4-C), 149.0 (2-C). Anal. Calcd for $\mathrm{C}_{12} \mathrm{H}_{14} \mathrm{NPF}_{6}$ (317.1): C, 45.45; H, 4.45; N, 4.42. Found: C, 44.83; H, 4.17; $\mathrm{N}, 4.40$.

\section{1-Ethyl-8-methyl-quinolinium-hexafluorophosphate (18)}

white-yellow crystals; mp $131{ }^{\circ} \mathrm{C}(36 \%$ yield $) ;{ }^{1} \mathrm{H}-\mathrm{NMR}\left(250 \mathrm{MHz}, \mathrm{CDCl}_{3}\right)$ : $\delta=1.58\left(\mathrm{t}, J=7.2 \mathrm{~Hz}, 2 \mathrm{H}, \mathrm{CH}_{2} \underline{\mathrm{CH}}_{3}\right), 2.64\left(\mathrm{~s}, 3 \mathrm{H}\right.$, Aromat- $\left.\underline{\mathrm{C}}_{3}\right), 5.12$ $\left(\mathrm{q}, J=7.2 \mathrm{~Hz}, 2 \mathrm{H}, \mathrm{N}^{+} \mathrm{C}_{2} \mathrm{CH}_{3}\right), 7.71(\mathrm{t}, J=8.7 \mathrm{~Hz}, 1 \mathrm{H}, 6-H), 7.83(\mathrm{~d}, \mathrm{~d}$ $J(6,7)=8.9 \mathrm{~Hz}, J(5,7)=1.8 \mathrm{~Hz}, 1 \mathrm{H}, 7-H), 7.89(\mathrm{t}, J=6.0 \mathrm{~Hz}, 1 \mathrm{H}, 3-H)$, $7.98(\mathrm{dd}, J(5,6)=8.9 \mathrm{~Hz}, J(5,7)=2.2 \mathrm{~Hz}, 1 \mathrm{H}, 5-H), 8.49(\mathrm{~d}, J=9.0 \mathrm{~Hz}$, $1 \mathrm{H}, 4-H), 9.32(\mathrm{dd}, J(2,3)=4.9 \mathrm{~Hz}, J(2,4)=1.2 \mathrm{~Hz}, 1 \mathrm{H}, 2-H) .{ }^{13} \mathrm{C}-\mathrm{NMR}$ $\left(63 \mathrm{MHz}, \mathrm{CDCl}_{3}\right): \delta=16.0$ (13-C), 19.6 (11-C), 53.0 (12-C), 118.4 (5-C), 120.5 (3-C), 130.7 (10-C), 131.1 (6-C), 138.7 (7-C), 144.3 (9-C), 145.4 (8-C), 147.5 (4-C), 149.8 (2-C). Anal. Calcd for $\mathrm{C}_{12} \mathrm{H}_{14} \mathrm{NPF}_{6}$ (317.1): C, 45.45; H, 4.45; N, 4.42. Found: C, 45.31; H, 4.33; N, 4.39.

\section{2,8-Dimethyl-1-ethyl-quinolinium-hexafluorophosphate (19)}

white-yellow crystals; mp $137{ }^{\circ} \mathrm{C}\left(18 \%\right.$ yield); ${ }^{1} \mathrm{H}-\mathrm{NMR}\left(250 \mathrm{MHz}, \mathrm{CDCl}_{3}\right)$ : $\delta=1.64\left(\mathrm{t}, J=7.3 \mathrm{~Hz}, 2 \mathrm{H}, \mathrm{CH}_{2} \underline{\mathrm{CH}}_{3}\right), 2.60\left(\mathrm{~m}, 6 \mathrm{H}\right.$, Aromat- $\left.\underline{\mathrm{H}}_{3}\right), 5.21$ $\left(\mathrm{q}, J=7.3 \mathrm{~Hz}, 2 \mathrm{H}, \mathrm{N}^{+} \mathrm{CH}_{2} \mathrm{CH}_{3}\right), 7.80(\mathrm{t}, J=8.9 \mathrm{~Hz}, 1 \mathrm{H}, 6-\bar{H}), 7.92$ $(\mathrm{dd}, J(5,6)=8.9 \mathrm{~Hz}, J(5,7)=2.1 \mathrm{~Hz}, 1 \mathrm{H}, 5-H), 7.99(\mathrm{~d}, \mathrm{~d} J(6,7)=9.0 \mathrm{~Hz}$, $J(5,7)=1.8 \mathrm{~Hz}, 1 \mathrm{H}, 7-H), 8.33(\mathrm{~d}, J=9.0 \mathrm{~Hz}, 1 \mathrm{H}, 3-H), 8.91(\mathrm{~d}, J=9.1 \mathrm{~Hz}$, $1 \mathrm{H}, 4-H) .{ }^{13} \mathrm{C}-\mathrm{NMR}\left(63 \mathrm{MHz}, \mathrm{CDCl}_{3}\right): \delta=15.9$ (13-C), 18.1 (11-C), 19,2 (14-C), 51.7 (12-C), 118.6 (5-C), 119.2 (3-C), 130.0 (10-C), 130.7 (6-C), 135.8 (7-C), 141.1 (9-C), 142.0 (4-C), 142.5 (8-C), 153.4 (2-C). Anal. Calcd for $\mathrm{C}_{13} \mathrm{H}_{16} \mathrm{NPF}_{6}$ (331.1): C, 47.12; H, 4.83; N, 4.23. Found: C, 46.81; H, 4.62; $\mathrm{N}, 4.20$.

\section{3-Methyl-1-(2'-sulfoethyl)-quinolinium-betaine (20)}

white crystals; $\mathrm{mp}>300{ }^{\circ} \mathrm{C}(83 \%$ yield $) ;{ }^{1} \mathrm{H}-\mathrm{NMR}\left(250 \mathrm{MHz}, \mathrm{D}_{2} \mathrm{O}\right): \delta=2.35$ $\left(\mathrm{s}, 3 \mathrm{H}\right.$, Aromat- $\left.\underline{\mathrm{H}}_{3}\right), 3.58\left(\mathrm{t}, J=7.2 \mathrm{~Hz}, 2 \mathrm{H}, \mathrm{CH}_{2} \underline{\mathrm{CH}}_{2} \mathrm{SO}_{3}\right), 5.07(\mathrm{t}, J=$ $\left.6.58 \mathrm{~Hz}, 2 \mathrm{H}, \mathrm{N}^{+} \underline{\mathrm{CH}}_{2} \mathrm{CH}_{2}\right), 7.64(\mathrm{t}, J=7.9 \mathrm{~Hz}, 1 \mathrm{H}, 6-H), 7.86(\mathrm{t}, J=8.6 \mathrm{~Hz}$, $1 \mathrm{H}, 7-H), 7.94(\mathrm{~d}, J=8.3 \mathrm{~Hz}, 1 \mathrm{H}, 5-H), 8.03(\mathrm{~d}, J=8.4 \mathrm{~Hz}, 1 \mathrm{H}, 8-H), 8.60$ $(\mathrm{s}, 1 \mathrm{H}, 4-H), 8.87(\mathrm{~s}, 1 \mathrm{H}, 2-H) .{ }^{13} \mathrm{C}-\mathrm{NMR}\left(63 \mathrm{MHz}, \mathrm{D}_{2} \mathrm{O}\right): \delta=17.7$ (11-C), 48.8 (13-C), 53.5 (12-C), 117.7 (5-C), 128.1 (10-C), 130.2 (6-C), 130.5 (8-C), 132.7 (3-C), 135.4 (7-C), 136.5 (9-C), 147.7 (4-C), 150.9 (2-C). Anal. Calcd for $\mathrm{C}_{12} \mathrm{H}_{13} \mathrm{NO}_{3} \mathrm{~S}$ (251.3): C, 57.30; H, 5.17; N, 5.57. Found: C, 57.38; H, 5.27; N, 5.49 .

\section{4-Methyl-1-(2'-sulfoethyl)-quinolinium-betaine (21)}

white crystals; $\mathrm{mp}>300{ }^{\circ} \mathrm{C}(86 \%$ yield $) ;{ }^{1} \mathrm{H}-\mathrm{NMR}\left(250 \mathrm{MHz}, \mathrm{D}_{2} \mathrm{O}\right): \delta=2.96$ $\left(\mathrm{s}, 3 \mathrm{H}\right.$, Aromat- $\left.\mathrm{C}_{3}\right), 3.60\left(\mathrm{t}, J=6.5 \mathrm{~Hz}, 2 \mathrm{H}, \mathrm{CH}_{2} \underline{\mathrm{H}}_{2} \mathrm{SO}_{3}\right), 5.34(\mathrm{t}, J=$ $\left.6.5 \mathrm{~Hz}, 2 \mathrm{H}, \mathrm{N}^{+} \underline{\mathrm{C}}_{2} \mathrm{CH}_{2}\right), 7.87(\mathrm{~d}, J=6.4 \mathrm{~Hz}, 1 \mathrm{H}, 3-H), 7.92(\mathrm{dt}, J(5,6,7)=$ 
$8.3 \mathrm{~Hz}, J(6,8)=1.1 \mathrm{~Hz}, 1 \mathrm{H}, 6-H), 8.16(\mathrm{dt}, J(6,7,8)=8.2 \mathrm{~Hz}, J(5,7)=$ $1.3 \mathrm{~Hz}, 1 \mathrm{H}, 7-H), 8.31(\mathrm{~d}, J=8.9 \mathrm{~Hz}, 1 \mathrm{H}, 5-H), 8.38(\mathrm{dd}, J(7,8)=8.5 \mathrm{~Hz}$, $J(6,8)=1.1 \mathrm{~Hz}, 1 \mathrm{H}, 8-H), 9.09(\mathrm{~d}, J=6.1 \mathrm{~Hz}, 1 \mathrm{H}, 2-H) .{ }^{13} \mathrm{C}-\mathrm{NMR}(63 \mathrm{MHz}$, $\left.\mathrm{D}_{2} \mathrm{O}\right): \delta=19.8$ (11-C), 48.9 (13-C), 53.3 (12-C), 118.3 (5-C), 122.4 (3-C), 127.4 (6-C), 129.6 (10-C), 129.8 (8-C), 135.8 (7-C), 136.9 (9-C), 148.8 (2-C), 160.9 (4-C). Anal. Calcd for $\mathrm{C}_{12} \mathrm{H}_{13} \mathrm{NO}_{3} \mathrm{~S}$ (251.3): C, 57.30; H, 5.17; N, 5.57. Found: C, 57.31; H, 5.19; N, 5.56.

\section{6-Methyl-1-(2'-sulfoethyl)-quinolinium-betaine (22)}

white crystals; $\mathrm{mp}>300{ }^{\circ} \mathrm{C}(77 \%$ yield $) ;{ }^{1} \mathrm{H}-\mathrm{NMR}\left(250 \mathrm{MHz}, \mathrm{D}_{2} \mathrm{O}\right): \delta=3.05$ $\left(\mathrm{s}, 3 \mathrm{H}\right.$, Aromat- $\left.\underline{\mathrm{H}}_{3}\right), 3.60\left(\mathrm{t}, J=6.7 \mathrm{~Hz}, 2 \mathrm{H}, \mathrm{CH}_{2} \mathrm{CH}_{2} \mathrm{SO}_{3}\right), 5.18(\mathrm{t}, J=$ $\left.6.7 \mathrm{~Hz}, 2 \mathrm{H}, \mathrm{N}^{+} \underline{\mathrm{C}}_{2} \mathrm{CH}_{2}\right), 7.89(\mathrm{~d}, J=8.3 \mathrm{~Hz}, 1 \mathrm{H}, 3-H), 8.12(\mathrm{dd}, J(7,8)=$ $8.2 \mathrm{~Hz}, J(5,7)=1.4 \mathrm{~Hz}, 1 \mathrm{H}, 7-H), 8.21(\mathrm{~d}, J=1.5 \mathrm{~Hz}, 1 \mathrm{H}, 5-H), 8.39(\mathrm{~d}, J=$ $8.3 \mathrm{~Hz}, 1 \mathrm{H}, 4-H), 8.89(\mathrm{dd}, J(7,8)=8.4 \mathrm{~Hz}, J(6,8)=1.3 \mathrm{~Hz}, 1 \mathrm{H}, 8-H), 9.31$ $(\mathrm{dd}, J(2,3)=7.7 \mathrm{~Hz}, J(2,4)=1.2 \mathrm{~Hz}, 1 \mathrm{H}, 2-H) .{ }^{13} \mathrm{C}-\mathrm{NMR}\left(63 \mathrm{MHz}, \mathrm{D}_{2} \mathrm{O}\right)$ : $\delta=21.4$ (11-C), 47.8 (13-C), 50.1 (12-C), 118.3 (5-C), 122.4 (3-C), 128.2 (6-C), 129.9 (8-C, 10-C), 134.3 (7-C), 136.7 (9-C), 140.9 (4-C), 146.6 (2-C). Anal. Calcd for $\mathrm{C}_{12} \mathrm{H}_{13} \mathrm{NO}_{3} \mathrm{~S}$ (251.3): C, 57.30; H, 5.17; N, 5.57. Found: C, 57.22; H, 5.10; N, 5.48.

\section{8-Methyl-1-(2'-sulfoethyl)-quinolinium-betaine (23)}

white crystals; $\mathrm{mp}>300{ }^{\circ} \mathrm{C}(33 \%$ yield $) ;{ }^{1} \mathrm{H}-\mathrm{NMR}\left(250 \mathrm{MHz}, \mathrm{D}_{2} \mathrm{O}\right): \delta=3.12$ $\left(\mathrm{s}, 3 \mathrm{H}\right.$, Aromat- $\left.\underline{\mathrm{H}}_{3}\right), 3.23\left(\mathrm{t}, J=6.9 \mathrm{~Hz}, 2 \mathrm{H}, \mathrm{CH}_{2} \mathrm{C}_{2} \mathrm{SO}_{3}\right), 5.09(\mathrm{t}, J=$ $\left.6.9 \mathrm{~Hz}, 2 \mathrm{H}, \mathrm{N}^{+} \underline{\mathrm{C}}_{2} \mathrm{CH}_{2}\right), 7.79(\mathrm{t}, J=8.6 \mathrm{~Hz}, 1 \mathrm{H}, 6-H), 7.85(\mathrm{~d}, J=8.6 \mathrm{~Hz}$, $1 \mathrm{H}, 3-H), 8.11(\mathrm{dd}, J(6,7)=8.1 \mathrm{~Hz}, J(5,7)=1.2 \mathrm{~Hz}, 1 \mathrm{H}, 7-H), 8.18(\mathrm{~d}, J=$

$8.7 \mathrm{~Hz}, 1 \mathrm{H}, 5-H), 8.36(\mathrm{~d}, J=8.6 \mathrm{~Hz}, 1 \mathrm{H}, 4-H), 9.31(\mathrm{dd}, J(2,3)=7.7 \mathrm{~Hz}$, $J(2,4)=1.2 \mathrm{~Hz}, 1 \mathrm{H}, 2-H) .{ }^{13} \mathrm{C}-\mathrm{NMR}\left(63 \mathrm{MHz}, \mathrm{D}_{2} \mathrm{O}\right): \delta=23.7$ (11-C), 49.2 (13-C), 52.3 (12-C), 117.9 (5-C), 122.0 (3-C), 127.1 (8-C), 128.0 (6-C), 128.4 (10-C), 132.1 (7-C), 135.9 (9-C), 143.3 (4-C), 150.1 (2-C). Anal. Calcd for $\mathrm{C}_{12} \mathrm{H}_{13} \mathrm{NO}_{3} \mathrm{~S}$ (251.3): C, 57.30; H, 5.17; N, 5.57. Found: C, 57.01; H, 5.07; $\mathrm{N}, 5.51$.

\section{2,8-Dimethyl-1-(2'-sulfoethyl)-quinolinium-betaine (24)}

white crystals; $\mathrm{mp}>300{ }^{\circ} \mathrm{C}(5 \%$ yield $) ;{ }^{1} \mathrm{H}-\mathrm{NMR}\left(250 \mathrm{MHz}, \mathrm{D}_{2} \mathrm{O}\right): \delta=3.36$ $\left(\mathrm{m}, 6 \mathrm{H}\right.$, Aromat- $\left.\underline{\mathrm{H}}_{3}\right), 3.68\left(\mathrm{t}, J=7.1 \mathrm{~Hz}, 2 \mathrm{H}, \mathrm{CH}_{2} \mathrm{CH}_{2} \mathrm{SO}_{3}\right), 5.56(\mathrm{t}, J=$ $\left.7.1 \mathrm{~Hz}, 2 \mathrm{H}, \mathrm{N}^{+} \mathrm{CH}_{2} \mathrm{CH}_{2}\right), 7.81(\mathrm{~d}, J=8.2 \mathrm{~Hz}, 1 \mathrm{H}, 3-H), 8.12(\mathrm{~d}, J=8.2 \mathrm{~Hz}$, $1 \mathrm{H}, 7-H), 8.21(\mathrm{~d}, J=8.2 \mathrm{~Hz}, 1 \mathrm{H}, 5-H), 8.39$ (d, $J=8.3 \mathrm{~Hz}, 1 \mathrm{H}, 4-H), 8.89$ $(\mathrm{t}, J=8.3 \mathrm{~Hz}, 1 \mathrm{H}, 6-H) .{ }^{13} \mathrm{C}-\mathrm{NMR}\left(63 \mathrm{MHz}, \mathrm{D}_{2} \mathrm{O}\right): \delta=20.9$ (14-C), 22.2 (11-C), 46.2 (13-C), 49.2 (12-C), 118.4 (5-C), 121.8 (3-C), 126.7 (6-C), 128.1 (10-C), 133.6 (7-C), 136.7 (9-C), 137.5 (8-C), 142.7 (4-C), 159.1 (2-C). Anal. Calcd for $\mathrm{C}_{13} \mathrm{H}_{15} \mathrm{NO}_{3} \mathrm{~S}$ (265.3): C, 58.80; H, 5.65; N, 5.28. Found: C, 58.70; H, $5.61 ; \mathrm{N}, 5.20$. 


\section{References}

1. G. J. Kavarnos, Fundamentals of Photoinduced Electron Transfer, VCH, New York (1993).

2. J. R. Bolton, N. Mataga and G. L. McLendon (Eds.), Electron Transfer in Inorganic, Organic and Biological Systems, American Chemical Society, Washington, DC (1991).

3. R. J. D. Miller, G. L. McLendon, A. J. Nozik, W. Schmickler and F. Willig, Surface Electron Transfer Processes, VCH, New York (1995).

4. A. M. Kuznetsov, Charge Transfer in Physics, Chemistry and Biology, Gordon and Breach, Luxembourg (1995).

5. V. Balzani (Ed.), Electron Transfer in Chemistry, Vol. 1-5, Wiley-VCH, New York (2001).

6. Vol. 3 of [104].

7. R. A. Marcus, Angew. Chem. 105 (1993) 1161.

8. P. Suppan, Topics in Current Chemistry, Vol. 163, Springer, Berlin (1992) p. 95.

9. J. V. Beitz and J. R. Miller, J. Chem. Phys. 71 (1979) 4579.

10. J. R. Miller, L. T. Calcaterra and G. L. Closs, J. Am. Chem. Soc. 106 (1984) 3047.

11. D. Rehm and A. Weller, Israel J. Chem. 8 (1970) 259.

12. I. R. Gould and S. Farid, Acc. Chem. Res. 29 (1996) 522.

13. C. Turro, J. M. Zaleski, Y. M. Karabatsos and D. G. Nocera, J. Am. Chem. Soc. 118 (1996) 6060.

14. P. Thanasekaran, T. Rajendran, S. Rajagopal, C. Srinivasan, R. Ramaraj, P. Ramamurthy and B. Venkatachalapathy, J. Phys. Chem. A 101 (1997) 8195.

15. E. Prasad and K. R. Gopidas, J. Am. Chem. Soc. 122 (2000) 3191.

16. H. Jiang, H. Xu and J. Ye, J. Chem. Soc., Perkin Trans. 2 (2000) 925.

17. M. D. Newton, Chem. Rev. 91 (1991) 767.

18. M. D. Newton, in: Vol. 1 of [104], p. 3.

19. V. Mujica, A. Nitzan, Y. Mao, W. Davis, M. Kemp, A. Roitberg and M. A. Ratner, Adv. Chem. Phys. 107 (1999) 403.

20. J. W. Verhoeven, Adv. Chem. Phys. 106 (1999) 603.

21. Th. Engel, Dissertation, Universität Würzburg (1996). (http://www2.chemie.unierlangen.de/services/dissonline/index.html)

22. Th. Stahl, Dissertation, Universität Würzburg (1992).

23. H. Lanig, T. Engel, G. Käb and F. W. Schneider, Chem. Phys. Lett. 235 (1995) 58.

24. H. Lanig, M. Hof, T. Stahl and F. W. Schneider, Chem. Phys. Lett. 220 (1994) 423.

25. H. Lanig, Dissertation, Universität Würzburg (1994).

26. G. Käb, Th. Engel, H. Lanig and F. W. Schneider, Ber. Bunsenges. Phys. Chem. 99 (1995) 118.

27. Th. Förster, Ann. Phys. 2 (1948) 55.

28. J. Jortner and M. Bixon, J. Chem. Phys. 88 (1988) 167.

29. B. Bagchi and N. Gayathri, Adv. Chem. Phys. 107 (1999) 1.

30. P. Suppan, Chimia 10 (1988) 31.

31. D. M. Ferguson and D. J. Raber, J. Am. Chem. Soc. 111 (1989) 4371.

32. N. L. Allinger, J. Am. Chem. Soc. 99 (1977) 8127.

33. G. Rauhut, A. Alex, J. Chandrasekhar and T. Clark, VAMP 5.0, Oxford Molecular LTD., Oxford (1993).

34. G. Rauhut, T. Clark and T. Steinke, J. Am. Chem. Soc. 115 (1993) 9174.

35. D. V. O'Connor and D. Phillips, Time-correlated Single Photon Counting, Academic Press, New York (1984).

36. T. H. Binkert, H. P. Tschanz and P. E. Zinsli, J. Lumin. 5 (1972) 187.

37. J. N. Demas, Excited Lifetime Measurement, Academic Press, New York (1983). 
38. D. A. H. Jacobs, The State of the Art in Numerical Analysis, Academic Press, London (1977).

39. D. W. Marquardt, J. Soc. Ind. Appl. Math. 11 (1963) 431.

40. J. Jaroszewska, I. Wawer and J. Oszczapowicz, Org. Magn. Reson. 22(5) (1984) 323.

41. A. Le Berre, A. Etienne and B. Dumaitre, Bull. Soc. Chim. France (1970) 954.

42. J. F. King, J. H. Hillhouse and S. Skonieczny, Can. J. Chem. 62 (1984) 1977.

43. O. S. Wolfbeis, E. Urbano, J. Heterocyclic Chem. 19 (1982) 841.

44. I. I. Ismail, Arch. Pharm. Res. 13 (1990) 1.

45. E. Ziegler, H. Wittmann, O. S. Wolfbeis and H. Sterk, Monatshefte f. Chemie 115 (1984) 1165.

46. A. L. Berre and A. Delacroix, Bull. Soc. Chim. France (1973) 2404.

47. A. Kirpal and B. Wojnar, Chem. Ber. 6 (1938) 1261.

48. J. F. King and M. Aslam, Tetrahedron Lett. 22 (1981) 3573.

49. H. Kampfer, M. Hase and M. Glass, Ger. Offen. 2803493 (1978) 36pp.

50. H. Kampfer and M. Glass, Ger. Offen. 2909200 (1980) 22pp.

51. W. Hünicke and R. Gauglitz, Ger. Offen. 3541098 (1987) 10pp.

52. R. Krapf, N. P. Illsley, H. C. Tseng and A. S. Verkman, Analyt. Biochem. 169 (1988) 142.

53. J. Willems, Bull. Soc. Chim. Belg. 64 (1955) 409, 747.

54. E. Ziegler, H. Wittmann, O. S. Wolfbeis and H. Sterk, Monatshefte f. Chemie 115 (1984) 1165. 